\title{
Transcriptome revealed the molecular mechanism of Glycyrrhiza inflata root to maintain growth and development, absorb and distribute ions under salt stress
}

Ying $X^{1,2}$, Jia-hui $L^{1,2,3,4^{*}}$, Jia-de Zhang ${ }^{1,2}$, Deng-kui Liu ${ }^{1,2}$, Yue Wang ${ }^{1,2}$, Qing-dong Niu ${ }^{1,2}$ and Dan-dan Huang ${ }^{1,2}$

\begin{abstract}
Background: Soil salinization extensively hampers the growth, yield, and quality of crops worldwide. The most effective strategies to counter this problem are a) development of crop cultivars with high salt tolerance and b) the plantation of salt-tolerant crops. Glycyrrhiza inflata, a traditional Chinese medicinal and primitive plant with salt tolerance and economic value, is among the most promising crops for improving saline-alkali wasteland. However, the underlying molecular mechanisms for the adaptive response of $G$. inflata to salinity stress remain largely unknown.

Result: G. inflata retained a high concentration of $\mathrm{Na}^{+}$in roots and maintained the absorption of $\mathrm{K}^{+}, \mathrm{Ca}^{2+}$, and $\mathrm{Mg}^{2+}$ under $150 \mathrm{mM} \mathrm{NaCl}$ induced salt stress. Transcriptomic analysis of $\mathrm{G}$. inflata roots at different time points of salt stress (0 min, $30 \mathrm{~min}$, and $24 \mathrm{~h}$ ) was performed, which resulted in $70.77 \mathrm{~Gb}$ of clean data. Compared with the control, we detected 2645 and 574 differentially expressed genes (DEGs) at $30 \mathrm{~min}$ and $24 \mathrm{~h}$ post-salt-stress induction, respectively. Gene Ontology (GO) and Kyoto Encyclopedia of Genes and Genomes (KEGG) pathway analyses revealed that G. inflata response to salt stress post $30 \mathrm{~min}$ and $24 \mathrm{~h}$ was remarkably distinct. Genes that were differentially expressed at 30 min post-salt stress induction were enriched in signal transduction, secondary metabolite synthesis, and ion transport. However, genes that were differentially expressed at $24 \mathrm{~h}$ post-salt-stress induction were enriched in phenylpropane biosynthesis and metabolism, fatty acid metabolism, glycerol metabolism, hormone signal transduction, wax, cutin, and cork biosynthesis. Besides, a total of 334 transcription factors (TFs) were altered in response to $30 \mathrm{~min}$ and $24 \mathrm{~h}$ of salt stress. Most of these TFs belonged to the MYB, WRKY, AP2-EREBP, C2H2, bHLH, bZIP, and NAC families.
\end{abstract}

Conclusion: For the first time, this study elucidated the salt tolerance in G. inflata at the molecular level, including the activation of signaling pathways and genes that regulate the absorption and distribution of ions and root growth in G. inflata under salt stress conditions. These findings enhanced our understanding of the $G$. inflata salt tolerance and provided a theoretical basis for cultivating salt-tolerant crop varieties.

Keywords: Glycyrrhiza inflata, Salt tolerance, RNA-Seq, Transcriptome analysis, Candidate genes

*Correspondence: jiahuil@shzu.edu.cn

${ }^{1}$ College of Life Science, Shihezi University, Shihezi 832003, Xinjiang, China

Full list of author information is available at the end of the article

\section{Background}

The area under saline-alkaline soil is continuously increasing due to climatic changes and agricultural production [1]. Soil salinity is a severe environmental abiotic stress, which hampers the productivity and quality 
of crops. It affects about 800 million hectares of land worldwide, including $30 \%$ of the world's highly productive irrigated land [2]. According to a prediction, nearly half of the world's arable land will be salinized by 2050 [3]. The best strategy to tackle this situation is developing and planting economically valuable salt-tolerant plants in saline-alkaline land [4].

In Chinese Pharmacopoeia (2015 edition), Glycyrrhiza inflata is one of the three Glycyrrhiza species of medicinal licorice [5]. It is mainly distributed in the Tarim Basin and the salt-alkali desert meadows of the Turpan-Hami basin in the Xinjiang region of China [6]. G. inflata thrives in saline-alkali abandoned farmlands. Besides, it positively affects the recovery of saline-alkaline abandoned farmland [7]. Salt tolerance of G. inflata is higher than Glycyrrhiza uralensis Fisch and Glycyrrhiza glabra L. Interestingly, G. inflata salt tolerance is much higher than commercial crops and forages of the same family, such as wild soybean and pea [8, 9]. Thus, G. inflata has a superior salt tolerance as well as economic and medicinal values. Also, it is one of the most efficient medicinal plants as far as the improvement of saline-alkaline abandoned farmland is concerned. However, the molecular mechanism for G. inflata salt tolerance remains largely unknown.

Plant growth, root development, and $\mathrm{Na}^{+}$accumulation in leaves reflect the plant's salt tolerance under salt stress conditions [10]. Hormonal signal transduction is involved in plant growth regulation and root development under salt stress conditions [11]. For instance, to regulate plant growth, abscisic acid (ABA) signals mediate the transmission of stress signals from root tips and regulate biological processes, such as stomatal conductance [12]. Ethylene reduces the number and elongation of root hairs [13]. The response of plant roots to salt stress can be categorized into four stages: a) stagnation period (root growth rate declines), b) quiescent period (slow root growth), c) recovery period (rapid increase in root growth rate), and d) equilibrium period (stable root growth). ABA signal regulates root growth recovery and lateral root stasis. Gibberellin (GA) and brassinosteroids (BR) signals promote salt stress-induced growth inhibition [11]. Previous studies have shown that $150 \mathrm{mM} \mathrm{NaCl}$ treatment for 21 days did not affect $G$. inflata root diameter, root length, and dry weight [9]. However, the underlying hormonal signaling and molecular mechanisms involved in the maintenance of G. inflata root growth and development remain elusive.

Storing ions in the roots is an effective way to reduce the sodium ion content in plant leaves [14]. Plants eliminate harmful ions from their roots, primarily at the structural and molecular levels. A vast array of harmful ions are blocked outside the stele by the endothelial barrier at the structural level. Moreover, ion transporters unload or transport harmful ions from the xylem to the extracellular space of plant cells at the cellular level. Thus, these harmful ions are either stored in the roots or excluded from the plants.

The endothelial barrier includes the apoplast barrier, i.e., Casparian strips (CS), and the transcellular barrier, i.e., suberin lamellae. The first stage of endothelial differentiation is the formation of the apoplast barrier. This apoplast barrier blocks the free diffusion of harmful ions into stele [15], which forces stele to pass through the endothelial barrier through either plasmodesmata mediated symplast pathway or ion transporters mediated transcellular pathway [16]. Chemical staining analysis of Arabidopsis thaliana showed that the CSs were mainly composed of lignin [17]. In the second stage of endothelial differentiation, suberin is deposited around the endothelial cells on the inner surface of the cell wall [18], inhibiting the transcellular pathway [19]. Suberin, a glycerin-based heteropolymer with a complex chemical structure, comprises aliphatic groups linked to phenolic components [20, 21]. As per previous studies, suberin confers salt tolerance to Arabidopsis by inhibiting $\mathrm{Na}^{+}$influx, $\mathrm{K}^{+}$efflux, and the recirculation of water [22].

Our previous studies have shown that under salt stress conditions, differentiation time of endodermis and synthesis of suberin lamella and CSs closer to the root tip are regulated, and $\mathrm{Na}^{+}$into the stele is blocked in G. inflata [9]. However, the underlying molecular mechanism remains unknown. $\mathrm{Na}^{+}$is retained in the root or excreted from the plant under salt stress conditions due to the presence of an ion transporter in the roots, which mediates the absorption of essential cations. For instance, salt overly sensitive 1 (SOS1), highaffinity $\mathrm{K}^{+}$transporter (HKT), and sodium/hydrogen antiporter (NHX) are primarily involved in the absorption, long-distance transportation, and distribution of $\mathrm{Na}^{+}$and $\mathrm{K}^{+}$[23]. However, ion transporters that play an active role in the response of G. inflata to salt stress remain ambiguous.

In recent years, a plethora of plant transcriptome data has been generated through next-generation sequencing technology. These data have enabled the identification of the molecular mechanisms of different plant species under different stress conditions, extending our current understanding of the molecular mechanisms of plant stress responses, such as Arachis hypogaea L. [24], Giant Juncao (Pennisetum spp.) [25], Brassica napus L. [26], and so on.

In the current study, RNA-seq of the G. inflata roots under salt stress at three different time points was obtained by employing the next-generation sequencing 
technology. This study aimed (1) to investigate the overall differences in the expression levels of $G$. inflata root genes, (2) to reveal the mechanism associated with the molecular response pathway involved in the maintenance of growth and development, and $\mathrm{Na}^{+}$retention and tolerance in G. inflata root at different salt stress stages, and (3) to discover the key genes that are involved in retention and tolerance of high concentration of $\mathrm{Na}^{+}$and growth and development of $G$. inflata roots.

\section{Result}

MDA content in G. inflata at different stages of salt stress Malondialdehyde (MDA) levels in roots and leaves of G. inflata did not increase continuously with increasing salt stress time. At certain time points of salt stress (roots: $10 \mathrm{~min} \sim 30 \mathrm{~min}, 6 \mathrm{~h} \sim 12 \mathrm{~h}, 24 \mathrm{~h} \sim 48 \mathrm{~h}$; leaves: $10 \mathrm{~min} \sim 1 \mathrm{~h}, 6 \mathrm{~h} \sim 12 \mathrm{~h}, 24 \mathrm{~h} \sim 48 \mathrm{~h}$ ), the MDA content change was either significantly lower or significantly unaltered compared to control (Fig. 1a). This indicated that the roots and leaves of $G$. inflata could resist or alleviate the oxidative stress induced by salt stress. The MDA content in G. inflata roots under salt stress was significantly higher than in leaves at any given time point, indicating that the oxidative damage in roots was higher under salt stress conditions.

$\mathrm{K}^{+}, \mathrm{Ca}^{2+}, \mathrm{Na}^{+}$, and $\mathrm{Mg}^{2+}$ content in G. inflata at the different time points of salt stress

The G. inflata roots and leaves $\mathrm{Na}^{+}$content ratio was 10.48 at $30 \mathrm{~min}$ and 43.86 at $48 \mathrm{~h}$ post-salt-stress

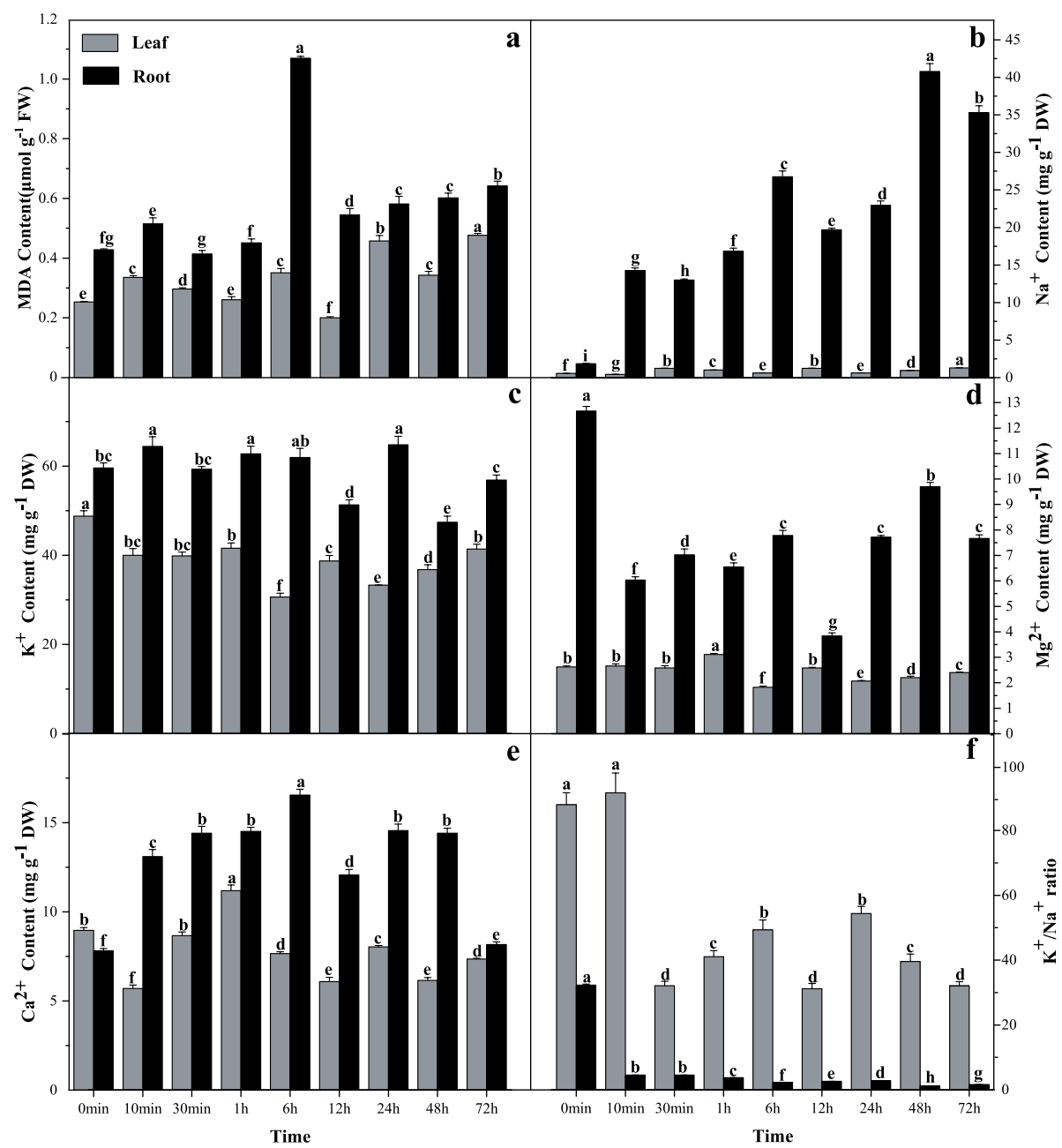

Fig. 1. G. inflata roots and leaves MDA and ion content at different time points of salt stress. a MDA content, $\mathbf{b} \mathrm{Na}^{+}$content, $\mathbf{c} \mathrm{K}^{+}$content, $\mathbf{d}$ $\mathrm{Mg} 2^{+}$content, e Ca2 ${ }^{+}$content, and $\mathbf{f ~} \mathrm{K}^{+} / \mathrm{Na}^{+}$ratio. 30-days-old $\mathrm{G}$. inflata seedlings were precultured in a standard nutrient solution and treated with $150 \mathrm{mM}$ of $\mathrm{NaCl}$ for $0 \mathrm{~min}, 10 \mathrm{~min}, 30 \mathrm{~min}, 1 \mathrm{~h}, 12 \mathrm{~h}, 24 \mathrm{~h}, 48 \mathrm{~h}$, and $72 \mathrm{~h}$. For each time point, three replicates were measured independently. Mean \pm SE $(n=3)$. Columns marked with the same letters were not significantly different based on the LSD test $(P<0.05)$ 
induction (Fig. 1b). This indicated that most of the $\mathrm{Na}^{+}$were mainly intercepted by the roots of $G$. inflata under salt stress conditions. This, in turn, significantly increased the $\mathrm{K}^{+} / \mathrm{Na}^{+}$ratio by $7.05 \sim 34.06$ folds in leaves than in root. Although the $\mathrm{K}^{+}$content of leaves was significantly lower than control (Fig. 1c), it did not decline with increasing salt stress at certain time points of salt stress $(10 \mathrm{~min} \sim 30 \mathrm{~min}, 1 \mathrm{~h} \sim 6 \mathrm{~h}, 12 \mathrm{~h} \sim 24 \mathrm{~h}$ ). In G. inflata roots, the $\mathrm{K}^{+}$content increased significantly at 0 to $10 \mathrm{~min}, 30 \mathrm{~min}$ to $6 \mathrm{~h}, 12$ to $24 \mathrm{~h}$, and 48 to $72 \mathrm{~h}$ post-salt-stress induction. At $10 \mathrm{~min}, 1 \mathrm{~h}, 6 \mathrm{~h}$, and $24 \mathrm{~h}$, the $\mathrm{K}^{+}$content of roots was significantly higher than the control. The $\mathrm{Mg}^{2+}$ level in roots did not decrease continuously with increasing salt stress time; however, it increased significantly at 10 to $30 \mathrm{~min}, 1$ to $6 \mathrm{~h}$, and 12 to $48 \mathrm{~h}$ post-salt-stress induction (Fig. 1d). In G. inflata leaves, the $\mathrm{Mg}^{2+}$ level was not significantly lower than control within $1 \mathrm{~h}$ of salt stress, but it increased significantly at 6 to $12 \mathrm{~h}$ and 24 to $72 \mathrm{~h}$ post-salt-stress induction. The $\mathrm{Ca}^{2+}$ content in the leaves showed a waveform change with increasing salt stress time (Fig. 1e). The $\mathrm{Ca}^{2+}$ content in the root of G. inflata is higher than the control at all time points after salt stress (Fig. 1e). The $\mathrm{Ca}^{2+}$ content in roots is highest at $6 \mathrm{~h}$ (approximately 2.12 folds of the control), and lowest at $72 \mathrm{~h}$ (approximately 1.05 folds of the control) post-salt-stress induction (Fig. 1e). The $\mathrm{Ca}^{2+}$ content in leaves is the highest at $1 \mathrm{~h}$ (approximately 1.25 folds of the control), and the lowest at $10 \mathrm{~min}$ (approximately 0.64 folds of the control) post-salt-stress induction (Fig. 1e). These results indicate that $G$. inflata has the ability to absorb $\mathrm{K}^{+}$, $\mathrm{Ca}^{2+}$, and $\mathrm{Mg}^{2+}$ under salt stress.

\section{Transcriptomic analysis in the root of $G$. inflata response to salt stress}

Transcriptome from the roots of G. inflata seedlings at three different salt stress time points was sequenced using Illumina 2000, and a total of nine transcriptome libraries were constructed (three library repeats for each time-point). Low-quality reads and the reads with poly- $\mathrm{N}$ were removed, and more than 40 million clean reads (Table S1) were obtained for each sample with Q30>92.82\% and GC\% between 44.49 to $44.74 \%$ (Table S2). The sequence output and quality met the set criteria, and sequences were thus further analyzed.

TopHat software was used to map the clean reads of each sample to the G. uralensis Fisch genome (http:// ngs-data-archive.psc.riken.jp/Gur-genome/). The proportion of total mapped reads ranged from 67.09 to $69.81 \%(31,413,445$ to $39,260,526$ reads) (Table S1). The gene expression levels were calculated and normalized using the TMM method; $\mid \log 2$ (FoldChange) $\mid>1$ and adjusted $p$-value $<0.05$ were set as the threshold for significant differential expression. A total of 2645 DEGs (1744 up-regulated and 901 down-regulated) and 574 (299 up-regulated and 275 down-regulated) DEGs were detected at $30 \mathrm{~min}$ and $24 \mathrm{~h}$ post-salt-stress induction, respectively compared to control (Fig. 2). The number of DEGs at $30 \mathrm{~min}$ time point was about five times higher than at $24 \mathrm{~h}$ time point. Venn analysis was performed to examine the differential expression of root tissue at different time points under salt stress conditions (Fig. 2C). With control as a reference, 164 DEGs intersected at $30 \mathrm{~min}$ and $24 \mathrm{~h}$, and 2481 DEGs intersected at $30 \mathrm{~min}$, and 410 DEGs intersected at $24 \mathrm{~h}$

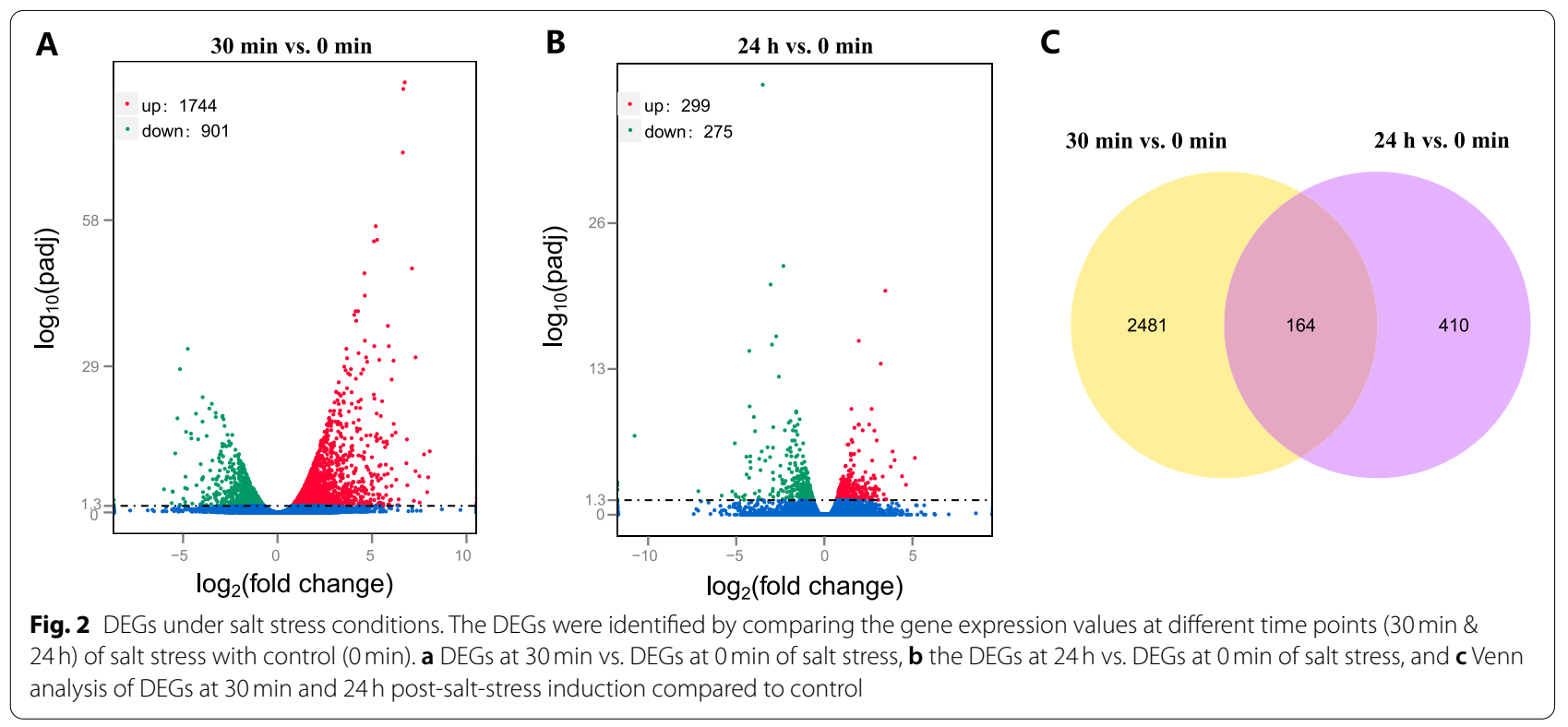


post-salt-stress induction. To validate the transcriptome data, expression levels of eight transcripts were determined using quantitative real-time PCR, and the outcomes were compared with RNA-seq data. We obtained a positive correlation coefficient $\left(R^{2}=0.86914\right)$ for these eight transcripts using linear regression analysis, which indicates the reliability of RNA-seq data (Fig. S1).

\section{Gene Ontology (GO) analysis of G. inflata DEGs under salt stress conditions}

To explore the functional significance of DEGs, up-and down-regulated DEGs from two different time points in salt stress conditions were subjected to GO analysis
(Fig. 3). A total of $17 \mathrm{GO}$ terms including "protein kinase activity," "metal ion binding," "nucleic acid binding transcription factor activity," "extracellular matrix," "macromolecule modification," and so on, were mainly enriched in the upregulated DEGs at $30 \mathrm{~min}$ post-salt stress induction. The DEGs down-regulated at $30 \mathrm{~min}$ of salt stress were only significantly enriched in the "oxidationreduction process." Furthermore, a total of 12 GO terms including "oxidation-reduction process," "response to oxidative stress," "movement of a cell or subcellular component," "antioxidant activity," "kinase activity," and so on, were mainly enriched in the upregulated DEGs at $24 \mathrm{~h}$ post-salt stress induction. The DEGs down-regulated at

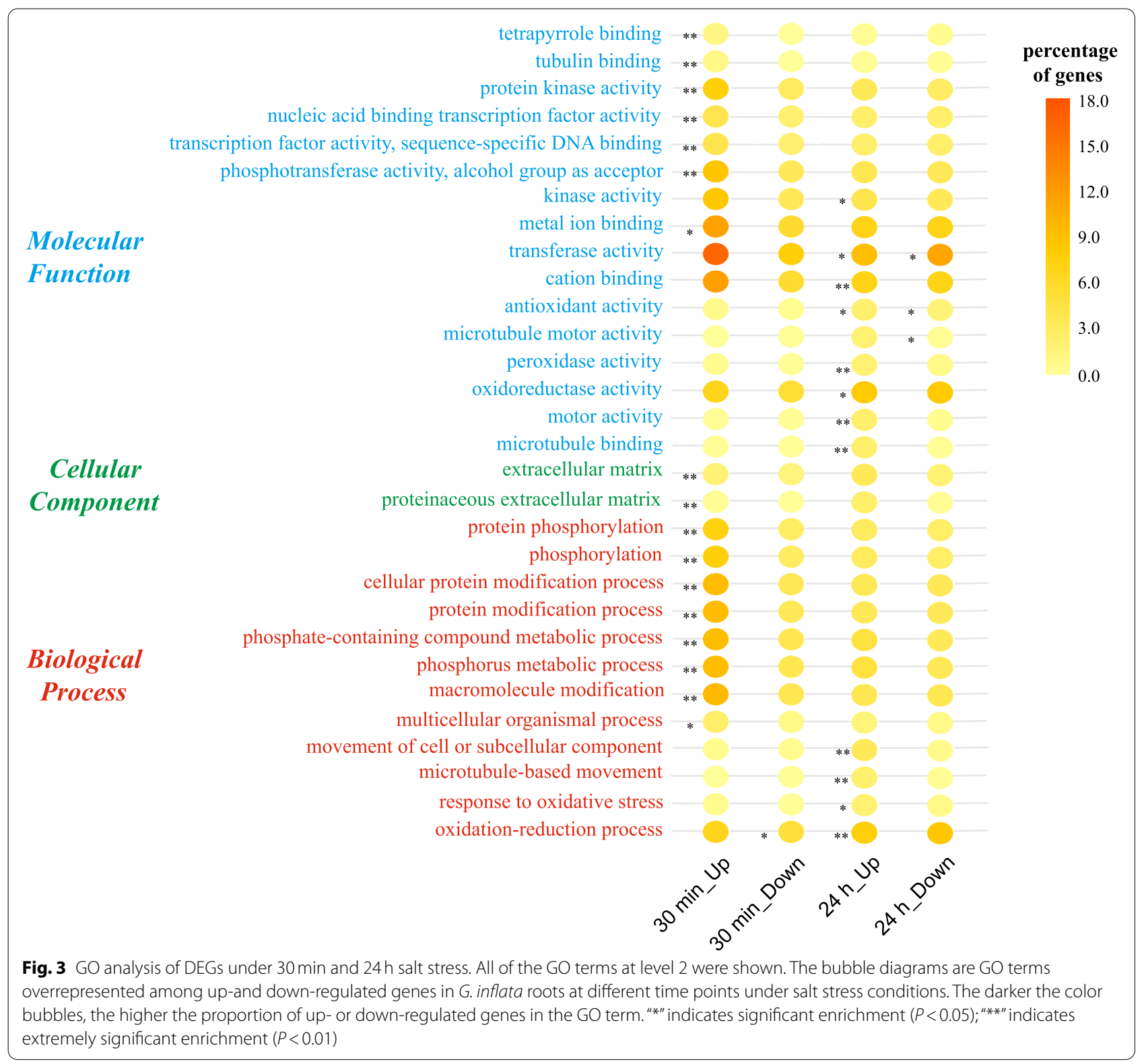


$24 \mathrm{~h}$ of salt stress were significantly enriched in "microtubule motor activity," "antioxidant activity," and "transferase activity."

\section{Kyoto Encyclopedia of Genes and Genomes (KEGG) pathway enrichment analysis of G. inflata DEGs under salt stress conditions}

To unravel the activation of biological pathways in G. inflata in response to salt stress, the KEGG pathway enrichment analysis of DEGs was performed. The results showed enrichment of metabolism and signal transduction pathways. The DEGs that were up-regulated at $30 \mathrm{~min}$ post-salt-stress induction were enriched in 89 biological pathways. Out of these 89 pathways, 4 signaling pathways, namely, plant-pathogen interaction, phosphatidylinositol signaling system, cysteine, and methionine metabolism, and alpha-linolenic acid metabolism, were significantly enriched. The down-regulated DEGs at $30 \mathrm{~min}$ post-salt-stress induction were enriched in 79 pathways. Out of these79 pathways, three pathways, namely, nitrogen metabolism, steroid biosynthesis, and biosynthesis of secondary metabolites were significantly enriched. The up-regulated DEGs at $24 \mathrm{~h}$ post-salt-stress induction were enriched in 47 biological pathways. Out of these 47 pathways, eight pathways, namely, phenylpropanoid biosynthesis, phenylalanine metabolism, biotin metabolism, fatty acid metabolism, fatty acid biosynthesis, glycerolipid metabolism, plant hormone signal transduction, and cutin, suberin, and wax biosynthesis were significantly enriched. The down-regulated DEGs from $24 \mathrm{~h}$ postsalt-stress induction were enriched in 68 biological pathways, but none of the pathways were significantly enriched (Fig. 4). Enrichment of these pathways might

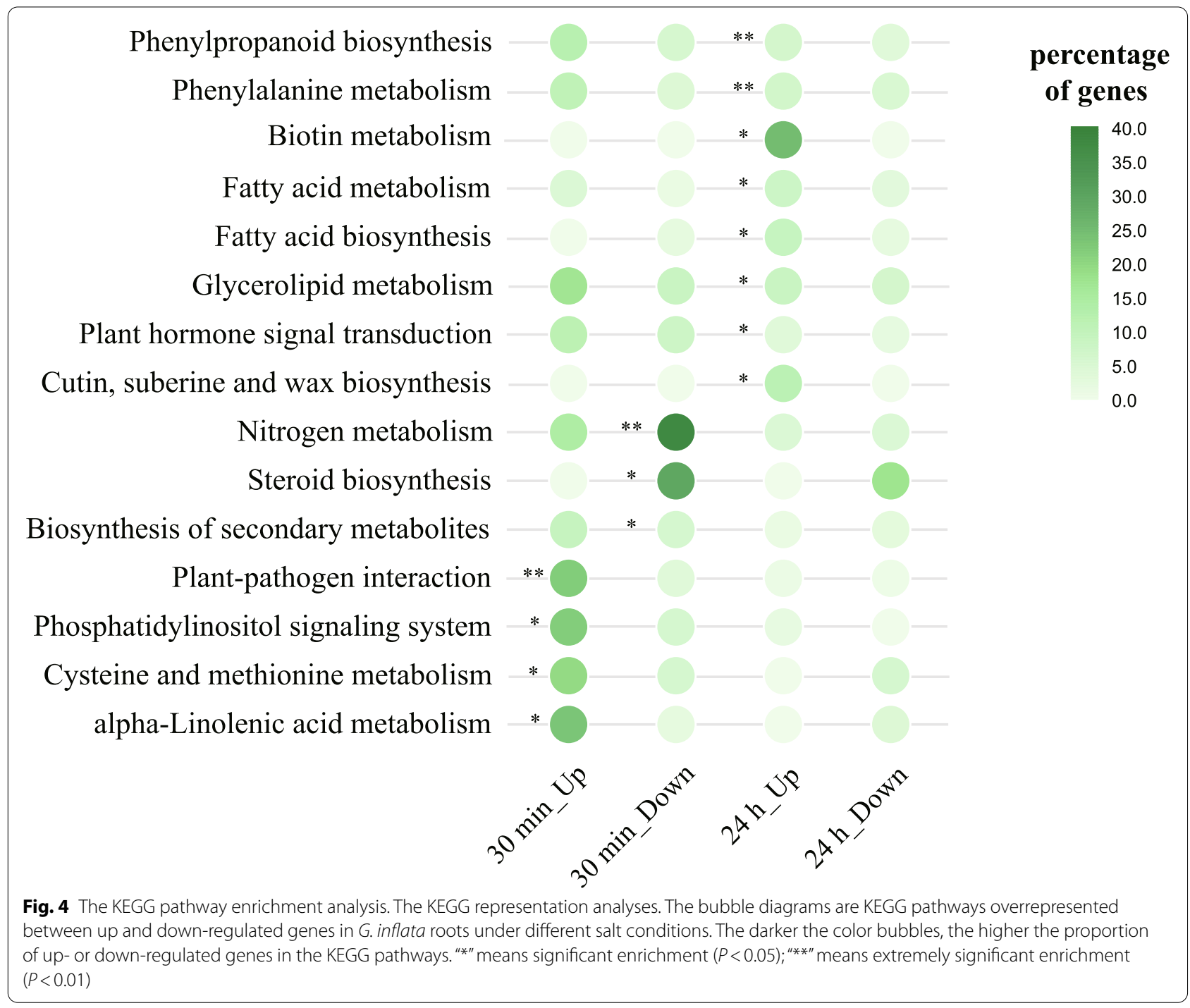


indicate their activation under salt stress conditions. Also, DEGs at $30 \mathrm{~min}$ and $24 \mathrm{~h}$ post-salt-stress induction were not enriched for a common biological pathway. This indicated that the salt response process of $G$. inflata is dynamic and has different response strategies to salt stress at different time points.

Activation of hormonal signal transduction in G. inflata roots in response to salt stress Phytohormones are involved in the regulation of plant growth and other biological processes as well as adaptation to stress conditions. In this study, we performed KEGG pathway enrichment analysis for DEGs expressed under salt stress conditions. The results suggested that salt stress induces activation of various hormonal signaling pathways, such as auxin, cytokinin, ABA, ethylene, jasmonic acid, salicylic acid, and so on in G. inflata root under salt stress (Fig. 5). Multiple genes related to ABA, auxin, and jasmonic acid signal transduction, were differentially expressed at $30 \mathrm{~min}$, but there was no significant change at $24 \mathrm{~h}$ post-salt-stress induction. These hormonal signaling may play an important role in the early response of $G$. inflata to salt stress. All DEGs involved in ethylene and salicylic acid signal transduction were down-regulated at $30 \mathrm{~min}$ and did not show significant change at $24 \mathrm{~h}$ postsalt-stress induction. Thus, we speculated that ethylene and salicylic acid signaling were inhibited at the initial stage of salt stress. The cyclin-D3-1 (CYCD3) coding gene expression, a response factor involved in BR signal transduction, did not change significantly at $30 \mathrm{~min}$, and it was up-regulated at $24 \mathrm{~h}$ post-salt-stress induction. We speculate that BR signaling may play a crucial role at $24 \mathrm{~h}$ post-salt-stress induction. The cytokinin receptor CER1 coding gene was down-regulated at $30 \mathrm{~min}$, and it did not change significantly at $24 \mathrm{~h}$ post-salt-stress induction. However, the expression pattern of the cytokinin response factor A-ARR encoding gene was not consistent with the CER1 expression, but the A-ARR encoding gene was up-regulated at $30 \mathrm{~min}$ and $24 \mathrm{~h}$ post-salt-stress induction.

The biosynthesis of secondary metabolites in G. inflata in response to salt stress In KEGG pathway enrichment analysis, 83 up-regulated and 52 down-regulated DEGs at $30 \mathrm{~min}$ post-salt-stress induction were enriched in the biosynthesis of secondary metabolites. Besides, 14 upregulated and 25 down-regulated DEGs at $24 \mathrm{~h}$ post-saltstress induction were enriched in the biosynthesis of the secondary metabolite pathway (Table S3). These DEGs were found to be involved in the synthesis of a variety of secondary metabolites, such as phenylpropanoids, suberin, hormones, steroids, flavonoids, and triterpenoids (Table S3).
DEGs enriched in the triterpenoid biosynthesis pathway were down-regulated at $30 \mathrm{~min}$ and had no significant differential expression at $24 \mathrm{~h}$ post-salt-stress induction (Fig. 6). Out of these DEGs, the Glyur000017s00002413 gene encoding squalene synthase plays a key role in triterpenoids biosynthesis. This indicates that triterpenoids biosynthesis in G. inflata was inhibited during the initial period of salt stress and reverted to a normal state at $24 \mathrm{~h}$ post-salt-stress induction. We speculate that the inhibitory effect of $150 \mathrm{mM} \mathrm{NaCl}$ salt stress on the triterpenoid biosynthesis in G. inflata is temporary.

The majority of the DEGs involved in the flavonoid biosynthesis were up-regulated at $30 \mathrm{~min}$ and had no significant change at $24 \mathrm{~h}$ post-salt-stress induction (Fig. 6). Thus, we speculated that short-term salt stress stimulates the flavonoids biosynthesis in G. inflata.

A total of 37 DEGs were found to be involved in phenylpropanoid biosynthesis and metabolism. These DEGs were also involved in the biosynthesis of lignin, caffeoylalcohol, cinnamaldehyde, and coumarin. Out of these 37 DEGs, 4 beta-glucosidase (BGL) protein-encoding DEGs were related to coumarin biosynthesis. DEGs related to the biosynthesis of caffeoyl-alcohol and cinnamaldehyde were up-regulated at $30 \mathrm{~min}$ and did not change significantly at $24 \mathrm{~h}$ post-salt-stress induction (Fig. 6). This indicated that the biosynthesis of caffeoyl-alcohol and cinnamaldehyde was activated in the early stage of salt stress. At $30 \mathrm{~min}$ post-salt-stress, we found that 11 up-regulated DEGs are related to the biosynthesis of lignin monomers. A total of 22 DEGs were identified as peroxidases (POX), involved in the catalysis of the lignin synthesis from the lignin monomer. Out of these 22 DEGs, 7 DEGs were up-regulated at $30 \mathrm{~min}$, and 7 DEGs were up-regulated at $24 \mathrm{~h}$ post-salt-stress induction. A total of $3 \mathrm{DEGs}$ involved in the cutin, suberin, and wax biosynthesis pathway, were up-regulated only at $24 \mathrm{~h}$ post-salt-stress induction. This indicates activation of the biosynthesis of cutin suberin and wax $24 \mathrm{~h}$ after post-salt-stress induction.

\section{Activation of other biological pathways in G. inflata in response to salt stress}

A majority of the genes involved in the interaction pathway between plants and pathogens were up-regulated at $30 \mathrm{~min}$ post-salt-stress induction. These genes include calcium-dependent protein kinase genes, disease-resistant protein genes, calcium-binding protein genes, WRKY transcription factors, and so on (Fig. S2). This indicates that this pathway is activated at the initial stage of salt stress and may transmit external environmental information in G. inflata. Thus, we speculated that it might play 


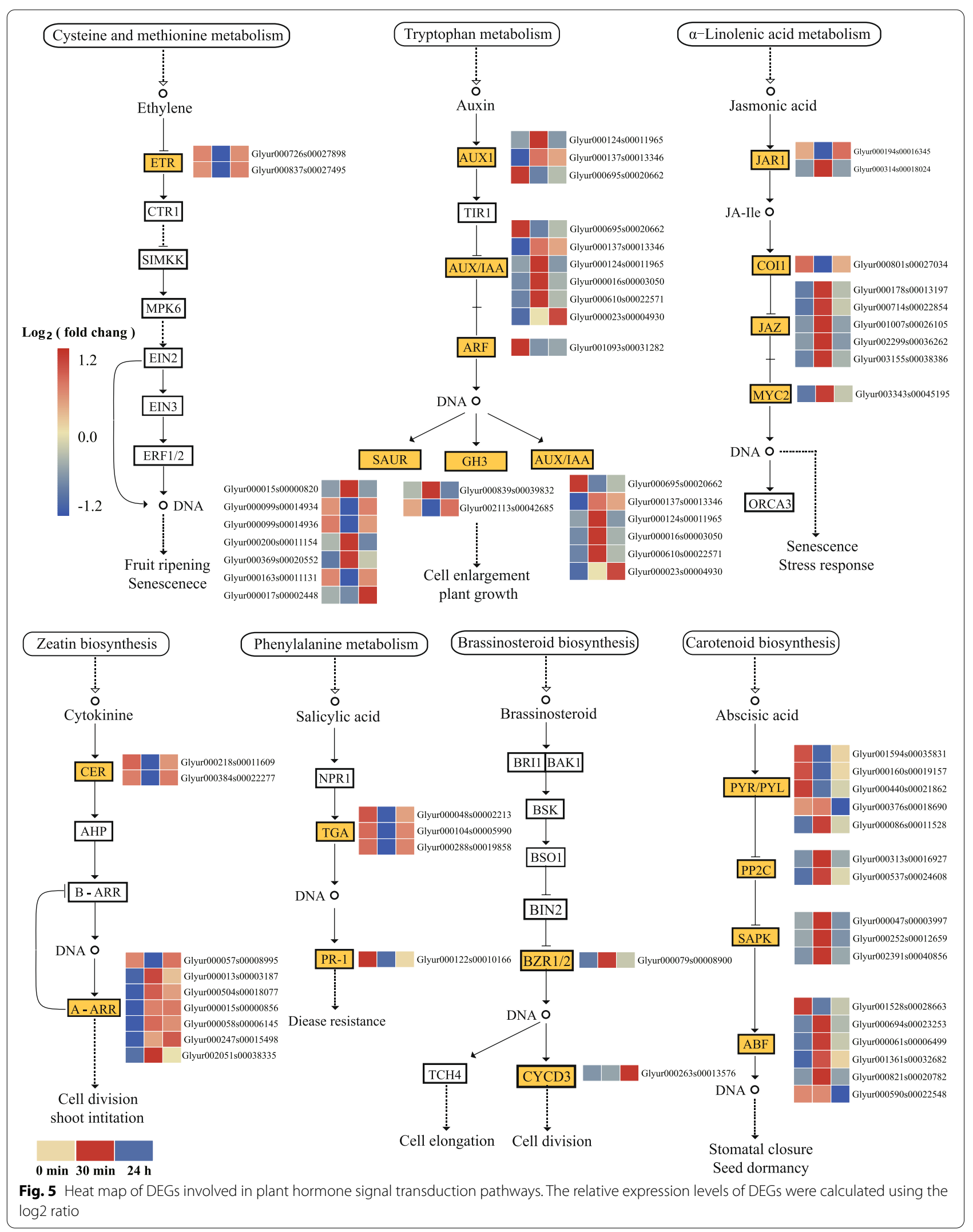




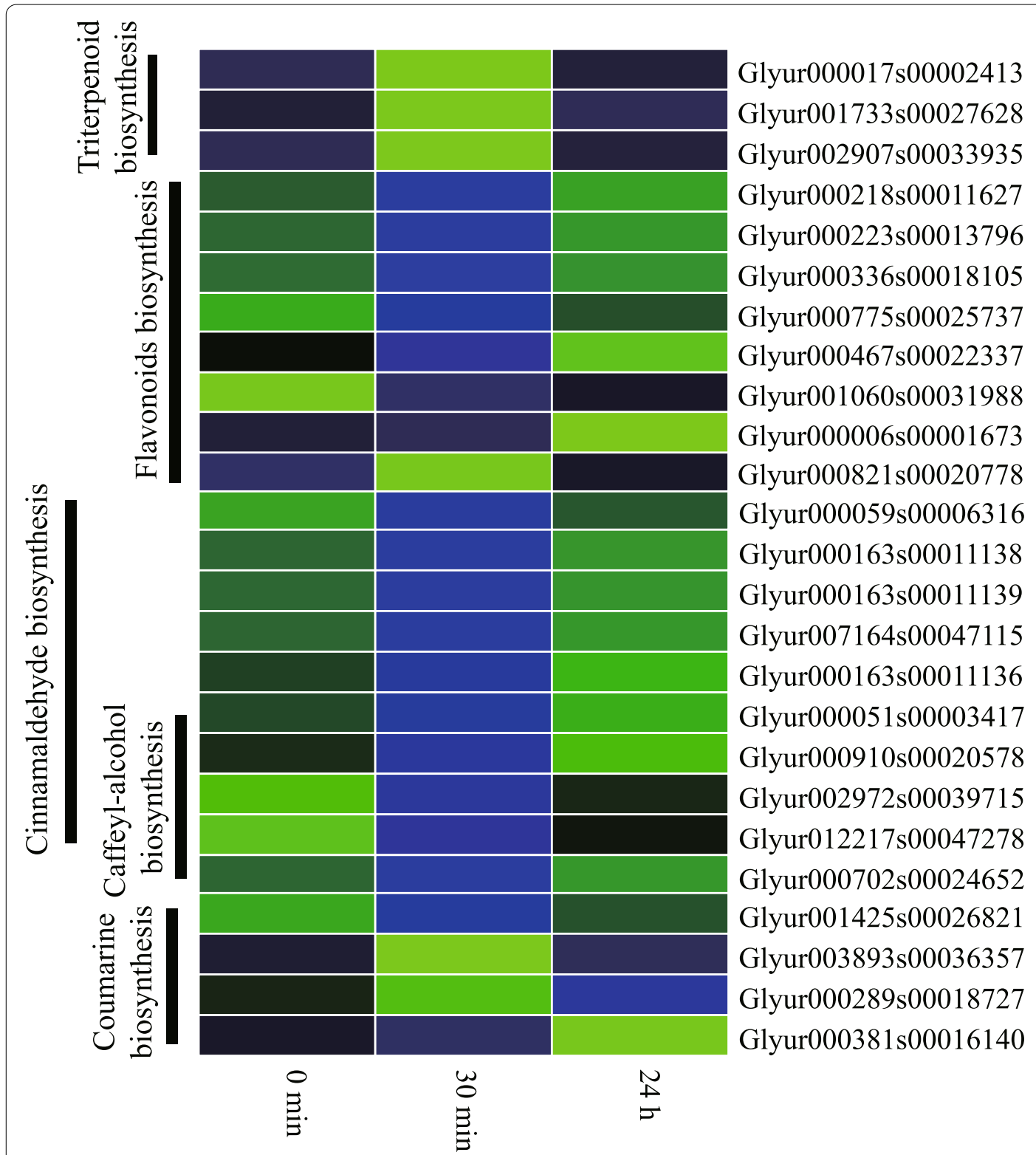

Fig. 6 DEGs involved in the biosynthesis of some secondary metabolites, including triterpenoid, flavonoids, caffeoyl-alcohol, cinnamaldehyde, and coumarin. The relative expression level of genes was calculated using the log 2 ratio

a vital role in the early adaptation of $G$. inflata to salt stress.

In KEGG pathway analysis, 14 DEGs were enriched in the phosphatidylinositol signaling system. Out of these 14 DEGs, 11 DEGs were up-regulated at $30 \mathrm{~min}$, and one DEG was up-regulated at $24 \mathrm{~h}$ post-salt-stress induction. This indicated that the enriched pathways were mainly activated at the early stage of salt stress (Fig. S3). Multiple studies have shown that these pathways are involved in signal transduction in response to stress, but the exact function of each element in this pathway remains largely unknown.

A total of 5 DEGs were enriched in fatty acid biosynthesis pathways, of which four genes were up-regulated only at $24 \mathrm{~h}$ post-salt-stress induction, and one gene was down-regulated at both $30 \mathrm{~min}$ and $24 \mathrm{~h}$ post-saltstress induction. These genes were involved in the biosynthesis of long-chain fatty acids. This indicates that the long-chain fatty acid biosynthesis was more active at $24 \mathrm{~h}$ post-salt-stress induction (Table S4). Out of 
the total 16 DEGs enriched in glycerolipid metabolic pathway (Table S5), three DEGs (Glyur000006s004755, Glyur000370s00222656, and Glyur001572s00035827) encoding glycerol-3-phosphate acyltransferase were up-regulated only at $24 \mathrm{~h}$ post-salt-stress induction.

\section{Transcription factors (TFs) in G. inflata in response to salt} stress

We found that a total of 334 DEGs were enriched as TFs. Most of these TFs belonged to the MYB, WRKY, AP2EREBP, C2H2, bHLH, bZIP, and NAC families (Fig. 7a).
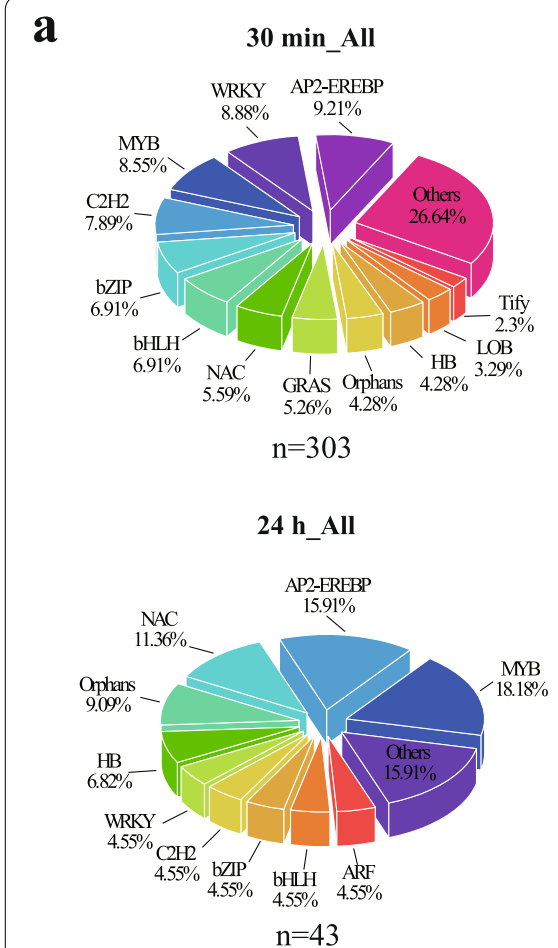

b
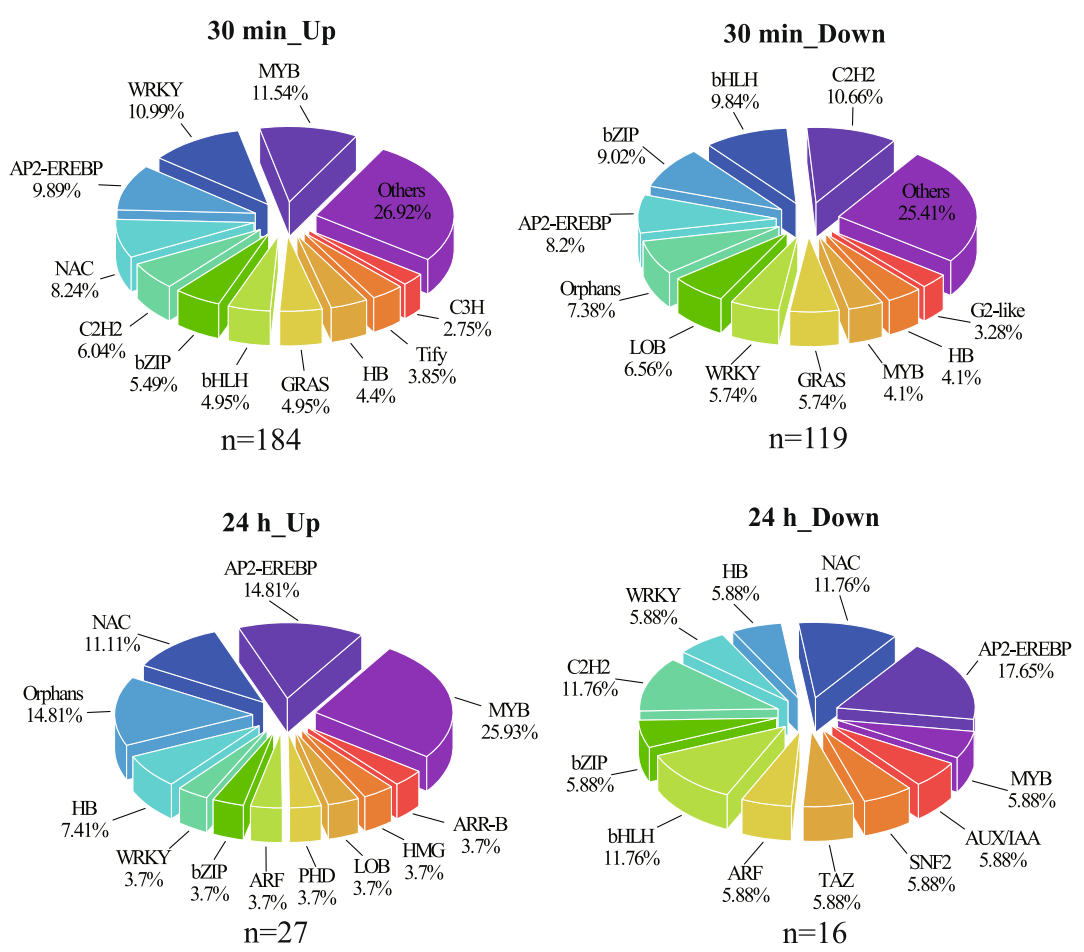

\begin{tabular}{|c|c|c|c|c|}
\hline & \\
\hline & & & 0.0 & \\
\hline Gene ID & Description & $0 \mathrm{~min}$ & $30 \mathrm{~min}$ & $24 \mathrm{~h}$ \\
\hline Glyur002051s00038335 & Two-component response regulator ARR9 [ Arabidopsis thaliana] & & & \\
\hline Glyur001933s00036045 & Transcription factor MYB39 [ Arabidopsis thaliana] & & & \\
\hline Glyur000101s00010324 & Basic leucine zipper 9 [Arabidopsis thaliana $]$ & & & \\
\hline Glyur001887s00036743 & Homeobox-leucine zipper protein HAT14 [ A rabidopsis thaliana ] & & & \\
\hline Glyur000202s00015418 & Ethylene-responsive transcription factor RAP2-3 [ Arabidopsis thaliana] & & & \\
\hline Glyur000186s00009857 & NAC domain-containing protein $21 / 22$ [ Arabidopsis thaliana] & & & \\
\hline Glyur000160s00019161 & SNF2 domain-containing protein CLASSY 1 [Arabidopsis thaliana] & & & \\
\hline Glyur001093s 00031282 & Auxin response factor 9 [Arabidopsis thaliana $]$ & & & \\
\hline Glyur000248s00011316 & NAC domain-containing protein 86 [ Arabidopsis thaliana] & & & \\
\hline Glyur000695s00020662 & Auxin-responsive protein IAA16 [ A rabidopsis thaliana ] & & & \\
\hline Glyur000177s00010902 & Zinc finger protein ZAT5 [Arabidopsis thaliana] & & & \\
\hline Glyur001395s 00031211 & Homeobox-leucine zipper protein ATHB-13 [ Arabidopsis thaliana ] & & & \\
\hline Glyur000001s00000134 & Transcription factor bHLH96 [Arabidopsis thaliana] & & & \\
\hline Glyur000647s00023061 & Pathogenesis-related genes transcriptional activator PTI6 [ Solanum lycopersicum ] & & & \\
\hline
\end{tabular}

Fig. 7 Transcription factors (TFs) differential expression in response to salt stress in G. inflata. a Statistics of up-regulated and down-regulated TFs induced by salt stress. $\mathbf{b}$ Differentially expressed TFs at $30 \mathrm{~min}$ and $24 \mathrm{~h}$ post-salt-stress induction 
Out of these 334 DEGs, 290 TFs were differentially expressed (178 up-regulated and 112 down-regulated) at $30 \mathrm{~min}$, and $30 \mathrm{TFs}$ were differentially expressed (22 upregulated and 8 down-regulated) at $24 \mathrm{~h}$ post-salt-stress induction. Besides, 14 TFs were differentially expressed (4 up-regulated and 9 down-regulated) at $30 \mathrm{~min}$ and $24 \mathrm{~h}$ post-salt-stress induction, and one TF were up-regulated at $30 \mathrm{~min}$ and down-regulated at $24 \mathrm{~h}$ post-salt-stress induction (Fig. 7b). We speculate that these 14 continuously differentially expressed TFs may play a crucial role in the response to salt stress of G. inflata.

\section{Ion transporters in $\mathrm{G}$. inflata in response to salt stress}

Transporters play a crucial role in the $\mathrm{Na}^{+}$absorption, transport, and chelation. We analyzed DEGs encoding ion transporters. After $30 \mathrm{~min}$ of salt induction, NHX2, HAK5, CCX5, CCX2, CHX15, HKT6, Atlg57610, and Atlg34470 were up-regulated, and HKT1, KAT3, and two-pore potassium channel 5 (TPK5) were down-regulated. Surprisingly, only TPK5 was down-regulated at $24 \mathrm{~h}$ post-salt-stress induction. This suggests that ion transporter primarily responds at the initial stage of salt stress (Fig. 8a).

\section{Discussion}

\section{G. inflata salt tolerance}

During the early stage of salt stress, the plant's water absorption capacity is reduced due to concomitant osmotic stress, resulting in ionic toxicity [27]. The core mechanism of salt stress response involves the transport of water and ions (mainly $\mathrm{Na}^{+}, \mathrm{Cl}^{-}$, and $\mathrm{K}^{+}$) between the plant and environment, as well as their redistribution between different plant parts and cellular compartments [28]. In this study, the $\mathrm{Na}^{+}$content in the G. inflata root was much higher than that in the leaves. This shows that most of the $\mathrm{Na}^{+}$absorbed from the environment were retained in the roots of $G$. inflata. Salt-tolerant plant species or genotypes commonly demonstrate a low $\mathrm{Na}^{+}$ accumulation in shoots and a high $\mathrm{Na}^{+}$accumulation in roots under salt stress conditions [29]. In halophytes or salt-tolerant plants, absorption, transportation, and separation of inorganic ions as osmotic regulators are costeffective methods to counter osmotic stress [30,31]. Due to low $\mathrm{Na}^{+}$accumulation in the leaves of G. inflata, the minimum $\mathrm{K}^{+} / \mathrm{Na}^{+}$ratio is 32.06 . A potassium-to-sodium ratio of about 1.0 is essential to maintain the steadystate of ions [32]. In G. inflata, the interception of $\mathrm{Na}^{+}$in the roots might be involved in the maintenance of a high $\mathrm{K}^{+}$/ $\mathrm{Na}^{+}$ratio and reduced ion toxicity in the shoots, and increased osmotic stress in the roots caused due to salt stress. However, overcoming the effects of response to salt stress is a highly challenging task for the cells in the G. inflata roots. High $\mathrm{Na}^{+}$accumulation decreases the level of other essential metal cations, such as $\mathrm{Ca}^{2+}$ and $\mathrm{Mg}^{2+}$, which in turn affects physiological and biochemical plant activities [33]. In this study, the levels of $\mathrm{K}^{+}$, $\mathrm{Ca}^{2+}$, and $\mathrm{Mg}^{2+}$ in G. inflata roots and leaves increased significantly at some stages of salt stress. This indicates that G. inflata can resist or alleviate the inhibitory effect of salt on the absorption of other essential metal cations, thereby maintaining normal growth and development. In summary, G. inflata has strong salt tolerance; it can

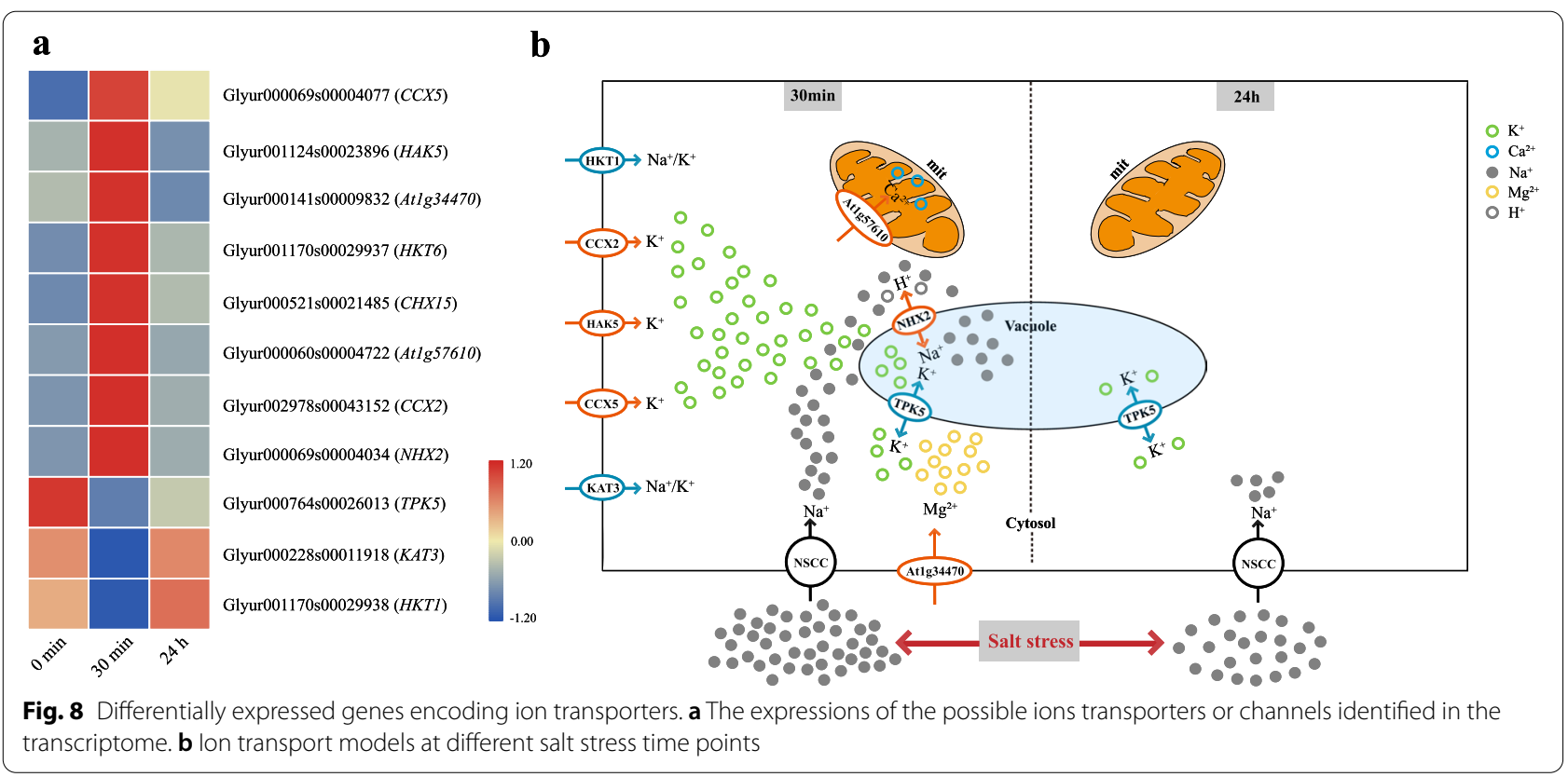


maintain the absorption of essential cations under salt stress and retain $\mathrm{Na}^{+}$in the roots.

It is worth mentioning that in addition to acting as an essential nutrient element for plants, $\mathrm{Ca}^{2+}$ also plays an important role in the process of information transmission [34]. With the increase of the salt stress time, the $\mathrm{Ca}^{2+}$ content in the roots and leaves of G. inflata shows a waveform change (Fig. 1e). Plants possess a rapid stress signaling system based on $\mathrm{Ca}^{2+}$ waves [35], which regulates various $\mathrm{Ca}^{2+}$-dependent enzymes and pathways to resist salt stress [36]. We speculate that the fluctuating changes of $\mathrm{Ca}^{2+}$ content in G. inflata under salt stress is the result of its comprehensive regulation in order to meet the needs of growth, development, and information transmission. The $\mathrm{Ca}^{2+}$ content in the root of G. inflata during $48 \mathrm{~h} \sim 72 \mathrm{~h}$ post-salt-stress induction decreased significantly from 1.844 times of the control to 1.05 times of the control (Fig. 1e). This is similar to the research results of Medicago sativa L. [37], Salicornia brachiate [38], Chloris virgata [39], etc. Abiotic stress can stimulate the efflux of $\mathrm{Ca}^{2+}$ in plants at certain moments [40]. The significant and continuous increase of $\mathrm{Ca}^{2+}$ results in irreversible damage to the cells [41]. We speculate that the significant decrease of $\mathrm{Ca}^{2+}$ content in $48 \sim 72 \mathrm{~h}$ of salt stress may represent a self-protection measure of G. inflata or the weakening of calcium signal. The physiological mechanism and significance involved in this process need to be further studied.

In addition to ionic and osmotic components, salt stress can also give rise to oxidative stress by increasing the levels of reactive oxygen species (ROS) [42]. MDA is the byproduct of damaged cell membrane caused due to higher ROS content than the threshold [43, 44]. Generally speaking, the longer the salt stress time, the higher is the MDA content. However, in the current study, the MDA content of G. inflata showed fluctuations and did not increase continuously with the increasing salt stress time; specifically, the MDA content in the roots of $G$. inflata decreased from 2.67 folds of the control to 1.36 folds during 6-12 h of salt stress (Fig. 1a). A large number of studies have shown that the plant antioxidant system can effectively remove ROS and reduce the damage caused by oxidative stress [45]. We speculate that G. inflata can activate the antioxidant system under salt stress conditions, alleviate lipid peroxidation caused due to oxidative stress.

\section{Regulation of ion transporter-mediated absorption and compartmentalization of ions in $G$. inflata roots under salt stress conditions}

The Glyur0000069s000004034 encoding NHX2 was upregulated $30 \mathrm{~min}$ post-salt-stress induction (Fig. 8a). The protein encoded by the $A t N H X 2$ gene separates the $\mathrm{Na}^{+}$ from the cytoplasm and store it in the vacuoles to prevent toxicity [46]. As $\mathrm{Na}^{+}$and $\mathrm{K}^{+}$have a similar ionic radius, certain $\mathrm{K}^{+}$transporters can mediate $\mathrm{Na}^{+}$absorption under salt stress conditions. In the current study, compared with the control, the Glyur001170s00029938 encoding HKT1 in G. inflata was down-regulated at $30 \mathrm{~min}$ post-salt-stress induction, and no significant change was observed $24 \mathrm{~h}$ post-salt-stress induction (Fig. 8a). These findings were in line with the previous study on salt tolerance in Gossypium hirsutum seedlings [47]. Kader et al. reported that the OsHKT1 down-regulation in salt-tolerant leaf mesophyll cells was due to hampered $\mathrm{Na}^{+}$transport in these metabolically active cells [48]. Thus, we speculate that NHX2 up-regulation and HKT1 down-regulation lead to the distribution of $\mathrm{Na}^{+}$to the vacuole and alleviation of $\mathrm{Na}^{+}$influx in $G$. inflata.

The Glyur001124s00023896 and Glyur000069s00004077 genes encoding HAK5 and CCX5, respectively, participate in $\mathrm{K}^{+}$transport. These genes were differentially up-regulated at $30 \mathrm{~min}$ post-salt-stress induction, and their expression levels did not change significantly at $24 \mathrm{~h}$ post-salt-stress induction (Fig. 8a). CCX5 and HAK5 can mediate $\mathrm{K}^{+}$absorption under low potassium and salt stress conditions $[49,50]$. Moreover, the OsHAK5 gene knockout mutant showed a reduced $\mathrm{K}^{+} / \mathrm{Na}^{+}$ratio in the shoot, indicating that OsHAK5 may be involved in $\mathrm{K}^{+}$distribution between roots and shoots [51]. In the current study, the $\mathrm{K}^{+}$level in G. inflata leaves was significantly higher at $30 \mathrm{~min}$ post-salt-stress than at $24 \mathrm{~h}$ post-salt-stress induction (Fig. 1c). This suggests that the Glyur001124s00023896 gene participated in longdistance $\mathrm{K}^{+}$transportation at $30 \mathrm{~min}$ post-salt-stress induction.

Glyur001170s00029937 and Glyur002978s00043152 genes encoding HKT6 and CCX2 were also differentially up-regulated $30 \mathrm{~min}$ post-salt-stress induction (Fig. 8a). However, no detailed study is available on the function and location of these genes. Glyur002978s00043152 gene, which encodes TPK5 protein, was down-regulated $30 \mathrm{~min}$ post-salt-stress induction (Fig. 8a). TPK5, a putative entity, encodes voltage-independent potassium channels that are located in the vacuoles. Five similar putative entities have been identified in A. thaliana, namely TPK1, TPK2, TPK3, TPK4, and KCO3. However, so far, only TPK1 and TPK4 have been explored [52]. We speculate that in G. inflata, vacuolar two-pore potassium channel activity is regulated through the TPK5 downregulation. This, in turn, reduces the $\mathrm{K}^{+}$transport from the cytoplasm into the vacuole and increases the storage space in the vacuole for the $\mathrm{Na}^{+}$, allowing $\mathrm{K}^{+}$participation in various biological processes, such as enzyme activation and protein synthesis in the cytoplasm. 
Glyur000060s00004722 gene, which encodes mitochondrial calcium uniporter (MCU), was differentially up-regulated at $30 \mathrm{~min}$ post-salt-stress induction (Fig. 8a). MCU5, a selective calcium channel located in the inner membrane of mitochondria, mediates $\mathrm{Ca}^{2+}$ influx [53] and plays a crucial role in calcium homeostasis in mitochondria and cells [54].

Interestingly, only one gene encoding TPK5 was downregulated $24 \mathrm{~h}$ post-salt-stress induction (Fig. $8 \mathrm{~b}$ ), suggesting a weak response of ion transporter to salt stress. Compared with $30 \mathrm{~min}$ of salt stress, the $\mathrm{K}^{+}, \mathrm{Na}^{+}$, and $\mathrm{Mg}^{2+}$ levels at $24 \mathrm{~h}$ increased significantly, and $\mathrm{Ca}^{2+}$ levels did not change significantly. $\mathrm{K}^{+}, \mathrm{Ca}^{2+}, \mathrm{Na}^{+}$, and $\mathrm{Mg}^{2+}$ levels at $24 \mathrm{~h}$ increased significantly compared to $12 \mathrm{~h}$ of salt stress; however, the $\mathrm{K}^{+} / \mathrm{Na}^{+}$ratio did not change significantly (Fig. 1). These results indicate that although the regulation of ion transporters was not significant at $24 \mathrm{~h}$ post-salt-stress induction, uptake of $\mathrm{K}^{+}, \mathrm{Ca}^{2+}$, and $\mathrm{Mg}^{2+}$ and basic ion homeostasis was maintained. We speculate that before $24 \mathrm{~h}$ of salt stress, G. inflata established new ions and osmotic pressure dynamic balance, mitigating the need for increased ion absorption and efflux.

\section{Sequestration of $\mathrm{Na}^{+}$into $\mathrm{G}$. inflata roots through CSs development under salt stress conditions}

The CSs acts as a physical barrier in the apoplast transport [55] and hinder the ion flow into the stele [56], and promote the plant response to different environmental stress conditions [57]. In the current study, we observed that most of the genes related to the biosynthesis of lignin, a crucial component of the CSs, were differentially up-regulated under salt stress conditions. Out of these lignin synthesis genes, PAL1, PAL3, PALY, 4CL2, CCR2, $C A D 6$, and $C Y P 84 A 1$ genes related to lignin monomer biosynthesis were differentially up-regulated at $30 \mathrm{~min}$ post-salt-stress induction. These genes catalyze the synthesis of $\rho$-Coumaric acid, ferulic acid, 5-Hydroxyferulic acid, and sinapic acid into $\mathrm{S}$-type, $\mathrm{H}$-type, $5 \mathrm{H}$, and G-type lignin monomer, respectively (Fig. 9). PAL catalyzed reaction is one of the rate-limiting steps in lignin synthesis. Also, increased expression and activity of PAL mostly signifies the environmental stress in plant tissues [58]. CYP84A1 gene encodes ferulate-5-hydroxylase (F5H). In comt deletion mutants, CYP84A1 overexpression resulted in the accumulation of $5 \mathrm{H}$ type suberin monomers; CYP84A1 overexpression resulted in S-type lignin monomers to account for $90 \%$ of the total lignin monomers $[59,60]$. We speculate that salt stress could stimulate G. inflata to produce H-type, S-type, G-type, and $5 \mathrm{H}$-type lignin monomers $30 \mathrm{~min}$ post-salt-stress induction.

As the lignin monomer synthesis does not occur directly in the cell wall but in the cytoplasm or near the endoplasmic reticulum [58], a series of transport mechanisms are required to make the lignin monomer pass through the cell membrane to reach the cell wall. The $\mathrm{ABC}$ transporter can be used to transport lignin monomers [61]. In the current study, we observed that a total of 12 genes encoding $A B C$ transporters are differentially up-regulated. Thus, we speculate that these genes might be involved in the transport of lignin monomers in response to salt stress in G. inflata.

The genes encoding LAC and POX were up-regulated at $30 \mathrm{~min}$ and $24 \mathrm{~h}$ post-salt-stress induction. The lignin monomers were oxidized and polymerized into lignin under the action of plant laccases (LAC) [62] and type III peroxidases (POX) [63]. The CASP1 and LAC3 were up-regulated at $24 \mathrm{~h}$ post-salt-stress induction, but their expression did not change significantly at $30 \mathrm{~min}$ postsalt-stress induction. As the cellular location of LAC, POX, and lignin varies, the site of lignin formation in the cell also varies. The condition for the CS formation is the lignin deposition in the formation area of the CS. CASP1 recruits peroxidase and proteins, such as PER64 and ESB1, related to lignin formation to accumulate in the formation area of the CS [61]. Thus, regulation of the CASP1 expression is essential for the CS membrane domain $\left(\mathrm{CSD}^{\mathrm{M}}\right)$ construction and CS formation [64]. Recent studies have reported the LAC3 regulated CS wall domain $\left(\mathrm{CSD}^{\mathrm{W}}\right)$ is spatially separated from $\mathrm{CSD}^{\mathrm{M}}$ by CASP1. Besides, $\mathrm{CSD}^{\mathrm{W}}$ works in coordination with $\mathrm{CSD}^{\mathrm{M}}$ for the precise lignification of CS [65]. We speculate that $G$. inflata responds to salt stress by forming CS at $24 \mathrm{~h}$ post-salt-stress induction.

In summary, G. inflata could respond to salt stress through lignin synthesis, increasing cell integrity, mechanical support, and water transport [66]. At 24h post -salt stress, in response to salt stress, CS formation could prevent $\mathrm{Na}^{+}$from entering the stele [56], thus responding to salt stress.

\section{Sequestration of $\mathrm{Na}^{+}$into $\mathrm{G}$. inflata roots through suberin lamellae development under salt stress conditions}

Suberin entails aliphatic, phenolic, and glycerin monomers [20], which are deposited around the endothelial cells on the inner surface of the cell wall to form suberin lamellae, blocking the transport of water and solutes through transcellular pathways. Thus, suberin is vital for conferring abiotic stress tolerance, such as salinity and drought in plants [18]. At 24h post-salt-stress induction, the up-regulated genes involved in phenylpropanoids, fatty acids, glycerides, and suberin biosynthesis, were significantly enriched in most biological pathways related to the biosynthesis and assembly of suberin monomers (Fig. 4). Thus, we speculate that at $24 \mathrm{~h}$ post-salt-stress 

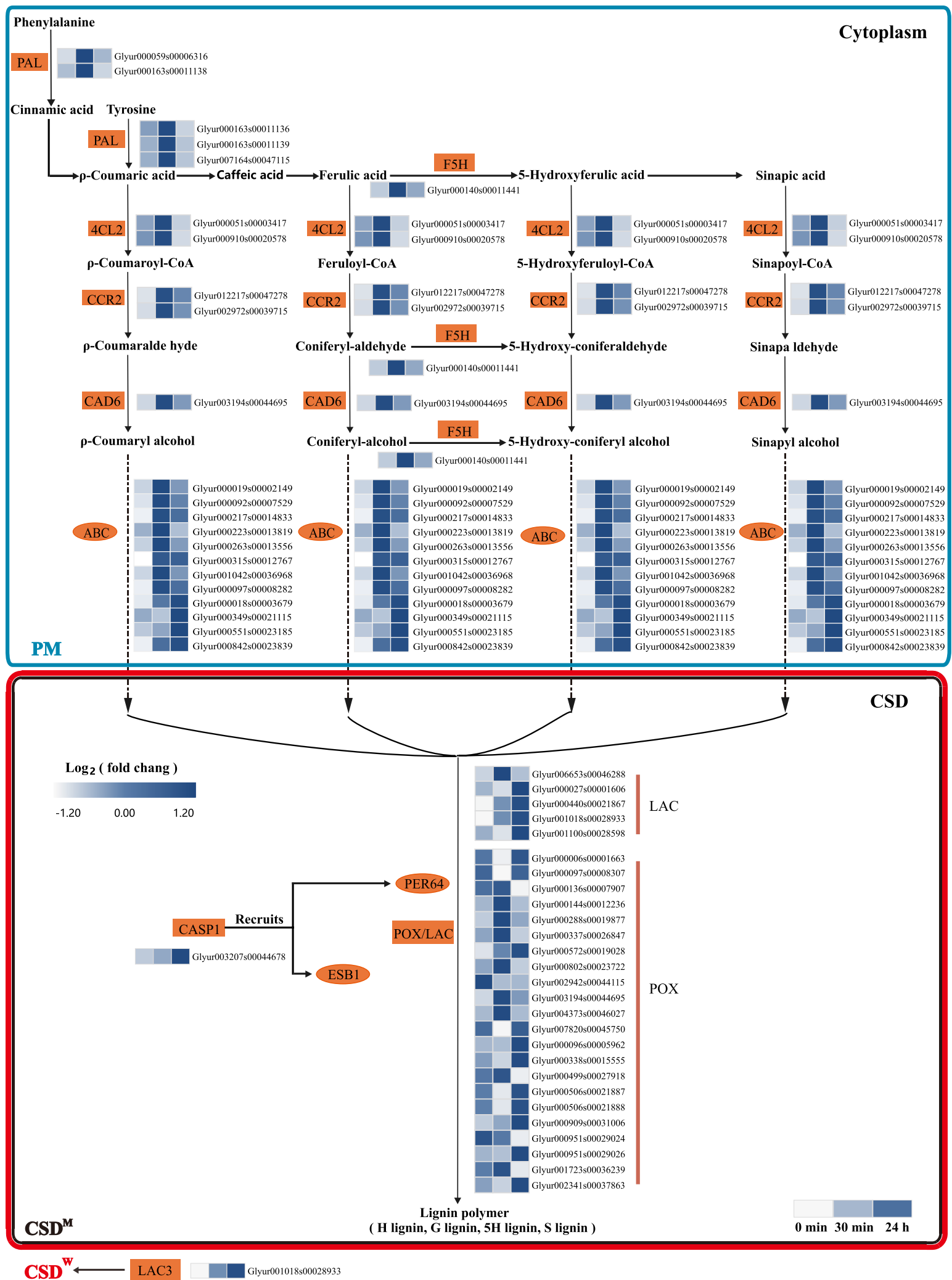

Fig. 9 Heat map of differentially expressed genes involved in lignin biosynthesis and Casparian strip formation under the different stages of salt stress 
induction, suberin biosynthesis increases in G. inflata in response to salt stress.

The aliphatic monomers of suberin include $\omega$-hydroxy fatty acids, $\alpha, \omega$-dicarboxylic acids, unsaturated fatty acids, medium-chain oxygenated fatty acids, and primary fatty alcohols [20, 64]. In the current study, we observed that salt stress stimulates the biosynthesis of aliphatic monomers $\omega$-hydroxy fatty acids and unsaturated fatty acids. The genes encoding CYP86A1 and CYP86B1 proteins were up-regulated at $24 \mathrm{~h}$ post-saltstress induction (Fig. 10). These enzymes promote the $\omega$-hydroxy fatty acid formation, of which CYP86A1 catalyzes the formation of short-chain $\omega$-hydroxy fatty acids from $\mathrm{C} 12$ to $\mathrm{C} 18$ fatty acids, which is particularly important in the early deposition of primary endodermis suberin [67]. CYP86B1 catalyzes the formation of long-chain omega-hydroxy fatty acids from C22 to C24 fatty acids [68]. We speculate that the synthesis of short-chain and long-chain omega-hydroxy fatty acids in G. inflata is more active at $24 \mathrm{~h}$ post-saltstress induction compared to control. The differential expression of genes encoding unsaturated lipases (FAD), which regulate fatty acid unsaturation, were up-regulated at $30 \mathrm{~min}$ and $24 \mathrm{~h}$ post-salt-stress induction (Fig. 11). The FAD7 was also up-regulated in barley roots under salt stress conditions [69]. We speculate FAD7 and FAD2-2 overexpression in G. inflata under salt stress conditions to enable increased synthesis of unsaturated fatty acids and suberin for countering the salt stress.

GPAT5 encoding GPATs proteins were up-regulated $24 \mathrm{~h}$ post-salt-stress induction. GPATs are primarily involved in transferring the acyl group of fatty acid acyl-CoA to the sn-2 position of glycerol triphosphate to produce monoacylglycerol [70]. Monoacylglycerol is the original suberin component [16]. Previous studies

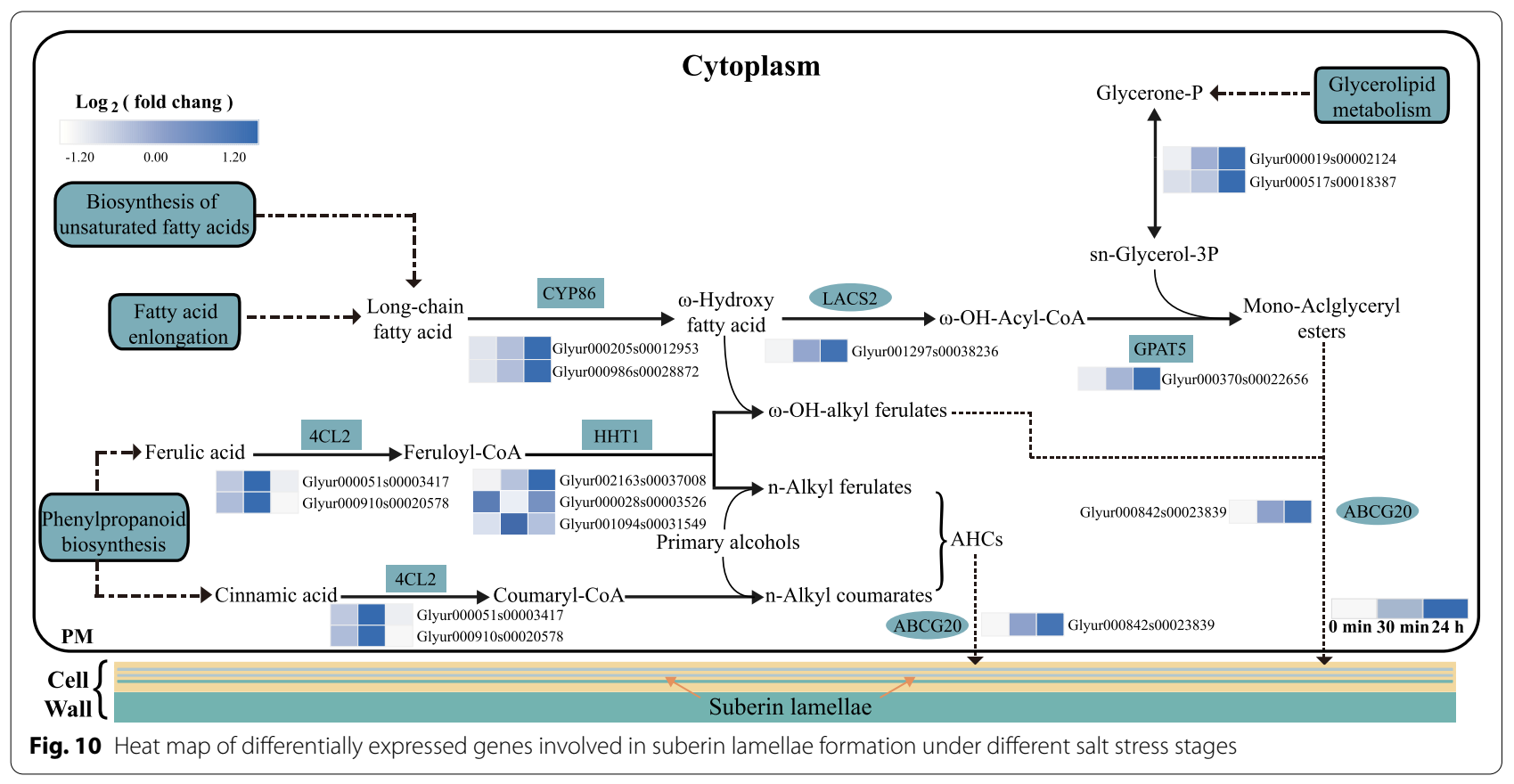

\begin{tabular}{|c|c|c|c|c|}
\hline & & \multicolumn{3}{|c|}{ 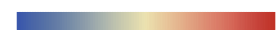 } \\
\hline & -1 & & 0.0 & 1.2 \\
\hline Gene ID & Description & $0 \min$ & $30 \mathrm{~min}$ & $24 \mathrm{~h}$ \\
\hline Glyur000954s00026538 & Very-long-chain 3-oxoacyl-CoA reductase 1 [Arabidopsis thaliana $]$ & & & \\
\hline Glyur000244s00014807 & Omega-6 fatty acid desaturase, endoplasmic reticulum isozyme [Glycine max ] & & & \\
\hline Glyur000305s 00025122 & 3-ketoacyl-CoA thiolase 2, peroxisomal [Arabidopsis thaliana $]$ & & & \\
\hline Glyur000455s00015977 & Omega-3 fatty acid desaturase, chloroplastic [Glycine $\max$ ] & & & \\
\hline Glyur000481s00027081 & Palmitoyl-monogalactosyldiacylglycerol delta-7 desaturase, chloroplastic [A rabidopsis thaliana] & & & \\
\hline
\end{tabular}

Fig. 11 Heat map of DEGs involved in the unsaturated fatty acid pathway. Relative expression was calculated by log2 ratio 
have shown that suberin level in roots of gpat5 mutant Arabidopsis was reduced by $50 \%$; however, the composition and content of membranes, stored glycerolipids, and surface waxes remain unchanged [71]. Also, long-chain acyl-CoA synthetase 2 gene LACS2 was up-regulated at $24 \mathrm{~h}$ post-salt-stress induction. LACS2 protein plays a crucial role in the $\omega$-hydroxyacyl-COA synthesis [72]. However, the involvement of this gene in the biosynthesis of suberin aliphatic monomers remains elusive. We believe that LACS2 is involved in converting suberin aliphatic monomer, $\omega$-hydroxy fatty acids are converted into $\omega$-hydroxyacyl-CoA under salt stress conditions. The main glycerol monomer of suberin is glycerol-3-phosphate (G-3-P). According to a current study, G-3-P biosynthesis in plants depends on glycerol kinases (GKs) [73], glycerol triphosphate dehydrogenase [74], and $\alpha$-glycerophosphate oxidase [75]. In the current study, we observed that the two genes encoding p-glycerol-3-phosphate dehydrogenase $\left[\mathrm{NAD}^{(+)}\right] 1$ were up-regulated at $24 \mathrm{~h}$ post-saltstress induction. The genes encoding this protein were also reported in the rice genome [76]. We speculated this gene might be involved in the synthesis of G-3-P under salt stress conditions. The phenolic monomers of suberin primarily include alkyl hydroxycinnamate (AHC), ferulic acid, coumaric acid, and lignin monomers [77]. Out of these phenolic monomers, the biosynthesis of lignin monomer and coumaric acid was found to be more active at $30 \mathrm{~min}$ post-salt-stress induction (Fig. 9). Ferulic acid generates ferulic acid acyl-CoA in a 4CL catalyzed reaction followed by transfer of acyl groups to $\omega$-hydroxy fatty acids and fatty alcohols in an ASFT/HHT catalyzed reaction to generate $\omega$-OH-alky-ferulates and n-Alky-ferulates [68]. In our study, the genes encoding $4 \mathrm{CL}$ were upregulated at $30 \mathrm{~min}$ of salt stress, and the genes encoding HHT1 were up-regulated at $30 \mathrm{~min}$ and $24 \mathrm{~h}$ of salt stress (Fig. 10). This indicates that salt stress stimulates the AHCs synthesis in G. inflata.

The suberin precursors synthesized in G. inflata under salt treatment, including monomers or partially formed oligomers, are transported from the endoplasmic reticulum to the plasma membrane where suberin lamellae are formed in the apoplast [21]. Thus, suberin transport is the key step to the formation of the suberin lamellae. In Arabidopsis, abcg2, abcg6, and $a b c g 20$ triple mutant were characterized by the suberin's altered structure, composition, and properties in the root and seed coat [78]. In the current study, Glyur000842s0023839, which encodes ABCG20 protein, was up-regulated $24 \mathrm{~h}$ post-salt-stress induction. This suggested that the Glyur000842s0023839 gene might be involved in the transport of monoacylglycerol, unsaturated fatty acid, alkyl hydroxycinnamate, coumaric acid, and lignin monomer and other suberin precursors from the cytoplasm to the cell wall for suberin lamellae formation.

In summary, the suberin phenolic monomers synthesis is more active at $30 \mathrm{~min}$, and the synthesis of suberin and suberin aliphatic monomers and glycerin monomers is more active at $24 \mathrm{hmin}$ post-salt-stress induction. ABCG20, which might be involved in the transport of suberin to apoplasts, is up-regulated at $24 \mathrm{~h}$ under salt stress. We speculate that $G$. inflata may respond to salt stress through suberin lamellae formation at $24 \mathrm{~h}$ and $30 \mathrm{~min}$ post-salt-stress induction.

\section{Hormonal signaling regulates root growth and development in $G$. inflata under salt stress conditions}

Salt tolerance is defined as the plant's ability to maintain its growth under saline stress [79]. Roots are the only plant part that directly encounters salt stress [80]. The growth and development of most plant roots are inhibited under salt stress conditions, making it difficult for plants to grow in a saline environment. Thus, the G. inflata root's ability to maintain growth and development under salt stress is the key to the strength of plant salt tolerance [78]. Under salt stress, plant hormones primarily regulate root growth and development, which requires tissue or cell-specific signaling networks [81]. In this study, we observed that auxin and abscisic acid signal transduction genes were mainly differentially expressed at $30 \mathrm{~min}$ post-salt-stress induction. However, ethylene, jasmonic acid, and salicylic acid signal transduction pathways were only differentially expressed at $30 \mathrm{~min}$ post-salt-stress induction. $\mathrm{BR}$ and cytokinin signal transduction pathways were continuously activated at $30 \mathrm{~min}$ and $24 \mathrm{~h}$ min post-saltstress induction.

Roots dynamically regulate growth and development in response to salt stress, which is restored after a period of transient growth inhibition [11]. Abscisic acid plays a crucial role in regulating lateral root growth and development under salt stress conditions [82]. The genes in this pathway encoding serine/threonine-protein kinase SAPK2 (SAPK2), serine/threonine-protein kinase SAPK3 (SAPK3), and serine/threonine-protein kinase SAPK7 (SAPK7) were all differentially up-regulated only at $30 \mathrm{~min}$ of salt stress (Fig. 5). SAPK7 and SAPK2 were expressed in the roots of seedlings [83]. SAPK2 and SAPK3 can phosphorylate BZIP46 along with ABI5, PP2C30, and PYL5 to regulate the growth and development of rice under drought stress conditions [84]. We speculate that SAPK2, SAPK3, and SAPK7 may positively affect the growth and development of the $G$. inflata roots under salt stress conditions. 
BR regulates root meristem size [85]. In our study, Glyur000079s00008900, the gene encoding the transcription factor BES1/BZR1 homolog protein 2 (BZR1/2), was upregulated at $30 \mathrm{~min}$ post-salt-stress induction. The gene Glyur000263s00013576, which encodes CYCD3, was upregulated at $24 \mathrm{~h}$ of salt stress induction. CYCD3 activity is crucial in determining cell number in developing lateral organs and the relative contribution of the alternative processes of cell production and cell expansion to overall organ growth [86]. Previous studies have shown that double mutants of cytokinin receptors, ahk2 and ahk3, form a root system with stronger absorptive capacity by increasing the growth rate of the primary root and lateral roots [87]. In this study, Glyur000218s00011609 gene, which encodes histidine kinase 2 (AHK2), and Glyur000384s00022277 gene, which encodes histidine kinase 3 (AHK3), was down-regulated at $30 \mathrm{~min}$ post-salt-stress induction. The regulation of plant root growth and development is a complex process. Different hormone signals have different effects on plant growth and development, and there is crosstalk between different hormones [88]. Thus, the plant root growth and development under salt stress conditions and its detailed physiological indicators demand an in-depth investigation.

\section{Conclusion}

In the current study, we obtained $70.77 \mathrm{~Gb}$ clean data from RNA-Seq analysis of G. inflata roots and identified 2645 and 574 DEGs at $30 \mathrm{~min}$ and $24 \mathrm{~h}$ post-saltstress induction, respectively. Most of the DEGs were found to be related to metabolism and signal transduction. A total of 334 TFs were differentially expressed in G. inflata. These findings indicate that DEGs involved in salt stress tolerance have a highly significant and complex role. In addition, the differential expression of genes related to ion transporters (NHX2, CCX5, HAK5, HKT1, HKT6, TPK5, MCU, KAT3), phenylpropanoid biosynthesis and metabolism (PAL1, PAL3, 4CL2, CCR2, CAD6, CYP84A1), cutin, suberin, and wax biosynthesis (CYP86A1, CYP86B1, HHT1), fatty acid biosynthesis and metabolism, glycerolipid biosynthesis (GPAT5), and endothelial barrier formation (CASP1, $L A C 3, A B C 20$ ) were involved in the regulation of the absorption and distribution of ions in the G. inflata cells and organ levels. Furthermore, certain differentially expressed genes related to plant hormone signal transduction (SAPK2, SAPK3, SAPK7, CYCD3, AHK2, $A H K 3$ ) were involved in the regulation of root growth and development of G. inflata under salt stress conditions. This study is the first to explain the salt tolerance of G. inflata at the molecular level. To a certain extent, the data from this study explain the underlying molecular mechanisms of salt tolerance in G. inflata.

\section{Materials and methods}

\section{Plant materials and salt treatment}

G. inflata seeds were procured from Licorice Research Institute, Shihezi University. These seeds were treated with $85 \%$ concentrated $\mathrm{H}_{2} \mathrm{SO}_{4}$ for $30 \mathrm{~min}$, immersed in $0.1 \% \mathrm{HgCl}_{2}$ solution for $10 \mathrm{~min}$, and rinsed 3-5 times with sterile water. Later these seeds were placed in a petri dish containing a moist filter paper and allowed to germinate at $25^{\circ} \mathrm{C}$ in an illumination incubator (GXZ430D) under dark conditions. 7-day-old seedlings with uniform size were transferred to a culture flask filled with containing modified Hoagland nutrient solution. The plants were placed under long-day (14h light $/ 10 \mathrm{~h}$ dark cycle) conditions at a temperature of $28^{\circ} \mathrm{C}$ (light) and $22^{\circ} \mathrm{C}$ (dark) with irradiation intensity ranging from $280 \sim 420 \mu \mathrm{mol} \cdot \mathrm{m}^{-2} \mathrm{~s}^{-1}$. To ensure the normal growth of seedlings, the nutrient solution was replaced every 3 days. 30-day-old seedlings were treated with a nutrient solution containing $150 \mathrm{mM} \cdot \mathrm{L}^{-1} \mathrm{NaCl}$. The seedlings were divided into two groups; one group was used for transcriptome sequencing and the other group for physiological analysis. For transcriptome sequencing, after $150 \mathrm{mM} \cdot \mathrm{L}^{-1} \mathrm{NaCl}$ treatment for $0 \mathrm{~min}$ (control), $30 \mathrm{~min}$, and $24 \mathrm{~h}$, the $\mathrm{G}$. inflata root samples were frozen using liquid nitrogen and stored at $-80^{\circ} \mathrm{C}$. Each treatment had three biological replicates. Root and leave samples at $0 \mathrm{~min}$ (control), $10 \mathrm{~min}, 30 \mathrm{~min}, 1 \mathrm{~h}, 6 \mathrm{~h}, 12 \mathrm{~h}, 24 \mathrm{~h}$, and $72 \mathrm{~h}$ were collected for MDA and ion level determination. In this treatment, each treatment had three biological replicates.

\section{MDA level determination}

Malondialdehyde (MDA) level was determined according to the method described by Hodges et al. [89]. $0.5 \mathrm{~g}$ of fresh leave and $0.5 \mathrm{~g}$ of root samples were homogenized in $4 \mathrm{~mL}$ of $0.1 \%(\mathrm{w} / \mathrm{v})$ trichloroacetic acid (TCA) using a vortex. The homogenate was centrifuged at $15,000 \times \mathrm{g}$ for $15 \mathrm{~min}$. The resulting $1 \mathrm{~mL}$ of the supernatant was mixed with $4 \mathrm{~mL}$ of TBA reagent $(0.5 \%$ of TBA in 20\% TCA). This reaction mixture was heated at $90^{\circ} \mathrm{C}$ for $20 \mathrm{~min}$ in a water bath and then quickly cooled in an ice bath. After centrifuging the samples at $13,000 \times \mathrm{g}$ for $8 \mathrm{~min}$, the absorbance of the supernatant was measured at 440,532 , and $600 \mathrm{~nm}$. MDA level was calculated using the following formula: MDA $\left(\mu \mathrm{mol} \cdot \mathrm{L}^{-1}\right)=6.45(\mathrm{D} 532-\mathrm{D} 600)-0.56 \mathrm{D} 450$.

\section{Ion concentration determination}

The G. inflata leave and root samples were first dried at $105^{\circ} \mathrm{C}$ for $10 \mathrm{~min}$ and then at $80^{\circ} \mathrm{C}$ to constant weight using 101-1A drying oven. Later, the dried samples were ground and sieved (30 mesh). The $65 \% \mathrm{HNO}_{3}$ and $30 \% \mathrm{H}_{2} \mathrm{O}_{2}$ (volume ratio 8:3) were added to the $100 \mathrm{mg}$ 
samples, and the resulting mixture was digested in a microwave digestion instrument (Multiwave 3000, Anton Paar $\mathrm{GmbH}$, Australia). The $\mathrm{Na}^{+}, \mathrm{K}^{+}, \mathrm{Ca}^{2+}$, and $\mathrm{Mg}^{2+}$ levels in the digested solution were determined using an inductively coupled plasma-optical emission spectrometer (Thermo Scientific ICAP 6000 Series, Boston, USA), as per the equipment operation manual.

\section{RNA extraction and quality determination}

Total RNA salt-treated root tissues $(0 \mathrm{~min}, 30 \mathrm{~min}$, and $24 \mathrm{~h}$ ) were extracted using TRIzol reagent. RNA degradation and contamination were monitored using $1 \%$ agarose gel. RNA purity was evaluated using the NanoPhotometer ${ }^{\circledR}$ spectrophotometer (IMPLEN, CA, USA). RNA concentration was measured using Qubit ${ }^{\circledR}$ RNA Assay Kit in Qubit ${ }^{\circledR}$ 2.0 Fluorometer (Life Technologies, CA, USA). RNA integrity was assessed using the RNA Nano 6000 Assay Kit of the Bioanalyzer 2100 system (Agilent Technologies, CA, USA).

\section{Sequencing library preparation for transcriptome}

A total of $3 \mu \mathrm{g}$ RNA per sample was used as input for the RNA sample preparation. Sequencing libraries were generated using NEBNext ${ }^{\circledR}$ Ultra $^{\mathrm{TM}}$ RNA Library Prep Kit for Illumina ${ }^{\circledR}$ (NEB, USA), as per manufacturer's instruction, and index codes were added to attribute sequences to each sample. Briefly, mRNA was purified from total RNA using poly-T oligo-attached magnetic beads. Fragmentation was carried out using divalent cations under elevated temperature in 5X NEBNext First Strand Synthesis Reaction Buffer. First-strand cDNA synthesis was carried using random hexamer primer and M-MuLV Reverse Transcriptase (RNase $\mathrm{H}-)$. Subsequently, second-strand cDNA synthesis was performed using DNA Polymerase RNase H. Overhangs and I were converted into blunt ends using exonuclease/polymerase activities. For hybridization, $3^{\prime}$ ends of DNA fragments were adenylated, and NEBNext Adaptor with hairpin loop structure was ligated. To select $150 \sim 200 \mathrm{bp}$ long cDNA fragments, the library fragments were purified using the AMPure XP system (Beckman Coulter, Beverly, USA). Then, $3 \mu$ l USER Enzyme (NEB, USA) was used with size-selected, adaptor-ligated cDNA at $37^{\circ} \mathrm{C}$ for $15 \mathrm{~min}$ followed by $5 \mathrm{~min}$ at $95^{\circ} \mathrm{C}$ before initiating PCR. PCR was performed using Phusion High-Fidelity DNA polymerase, Universal PCR primers, and Index (X) Primers. Lastly, PCR products were purified (AMPure XP system), and library quality was assessed on the Agilent Bioanalyzer 2100 system. Libraries were sequenced on an Illumina HiSeq 2000 platform to generate paired-end reads of $125 \mathrm{bp} / 150 \mathrm{bp}$ long reads.

\section{Data analysis}

Raw data (raw reads) of FastQ format were processed using in-house Perl scripts. In this step, clean data (clean reads) were obtained by removing reads containing adapter. Reads containing ploy- $\mathrm{N}$ and low-quality reads from raw data. Q20, Q30 scores, and GC content of the clean data were also calculated. Before downstream analysis, the clean reads in each sample were mapped to the Glycyrrhiza uralensis genome database (http://ngs-data-archive.psc.riken.jp/Gur-genome/) using TopHat version 2.0.12.

HTSeq version 0.6.1 was used to count the read numbers mapped to each gene. Then, the FPKM value of each gene was calculated based on the gene length and read counts. Differential expression analysis of two conditions/groups (two biological replicates per condition) was performed using the DESeq $\mathrm{R}$ package version 1.18.0. The $P$-values were adjusted using Benjamini and Hochberg's approach to limit the false discovery rate. Genes with an adjusted $P$-value $<0.05$ obtained through DESeq were termed as differentially expressed genes. Differential expression analysis of two conditions was performed using the DEGSeq R package version 1.20.0. The $P$-values were adjusted using the Benjamini \& Hochberg method. Corrected $P$-value of 0.005 and $\log _{2}$ fold change of 1 was set as the threshold for significantly differential expression.

Gene Ontology (GO) enrichment analysis of differentially expressed genes with corrected gene length bias was performed using the GOseq $\mathrm{R}$ package. GO terms with corrected $P$-value $<0.05$ were considered significantly enriched. Besides, DEGs were subjected to KEGG pathway enrichment analysis. The statistical enrichment of DEGs was tested using the KOBAS version 2.0 web server, and the corrected $P$-value $<0.05$ was considered to be significantly enriched in KEGG.

\section{Quantitative real-time PCR}

To validate the accuracy of the RNA-seq results, RealTime quantitative PCR (RT-qPCR) analysis was performed. cDNAs were synthesized from RNA extracted from plants before $(0 \mathrm{~min})$ and after $(30 \mathrm{~min}, 24 \mathrm{~h})$ the salt stress treatments by using RevertAid ${ }^{\mathrm{TM}}$ First Strand cDNA Synthesis Kit (Thermo, USA). RT-qPCR analysis was performed as described previously [90]. Glycyrrhiza inflata Bat. $18 \mathrm{~S}$ rRNA was used as an internal control. The qRT-PCR primers are listed in Table S6.

\section{Abbreviations}

DEGs: Differentially expressed genes; GO: Gene Ontology; KEGG: Kyoto Encyclopedia of Genes and Genomes; TFs: Transcription factors; ABA: Abscisic acid; GA: Gibberellin; BR: Brassinosteroids; CS: Casparian strips; SOS1: Salt 
overly sensitive 1; HKT: High-affinity K+ transporter; NHX: Sodium/hydrogen antiporter; MDA: Malondialdehyde; BGL: Beta-glucosidase; POX: Peroxidases; MYB: Myeloblastosis; bHLH: Basic helix-loop-helix; bZIP: Basic leucine zipper; NAC: NAM no apical meristem; NHX: $\mathrm{Na}^{+} / \mathrm{H}^{+}$exchanger; HAK5: Potassium transporter 5; CCX: Cation/calcium exchanger; KAT3: Potassium channel KAT3; TPK: Two-pore potassium channel; MCU: Mitochondrial calcium uniporter; CS: Casparian strip; PAL: Phenylalanine ammonia lyase; 4CL2: 4-coumarate--CoA ligase 2; CCR2: C-C chemokine receptor type 2; F5H: Ferulate-5-hydroxylase; LAC: Laccases; CSDM: CS membrane domain; CSDW: CS wall domain; FAD: Unsaturated lipases; GPAT: Glycerol-3-phosphate acyltransferase; G-3-P: Glycerol-3-phosphate; AHCs: Alkyl hydroxycinnamate; 4CL: 4-coumarate-CoA ligase; ABC: ATP-binding cassette; ABCG20: ABC transporter $G$ family member 20; BZR1/2: BES1/BZR1 homolog protein 2; CYCD3: Cyclin-D3-1; RT-qPCR: RealTime quantitative PCR.

\section{Supplementary Information}

The online version contains supplementary material available at https://doi. org/10.1186/s12870-021-03342-6.

\section{Additional file 1. \\ Additional file 2 . \\ Additional file 3. \\ Additional file 4. \\ Additional file 5.}

Additional file 6.

Additional file 7.

Additional file 8.

Additional file 9.

\section{Acknowledgements}

Not applicable.

\section{Authors' contributions}

$\mathrm{LJH}$ designed and directed the study and revised the manuscript; XY analyzed the data and wrote the manuscript; WY and NQD performed the experiments; ZJD, LDK, and HDD have made important contributions to the literature search for $G$. inflata salt tolerance (add article: $[6,7,9,31]$ ) and the data compilation of the phosphatidylinositol signaling system pathway. All authors read and approved the final manuscript.

\section{Funding}

This study was supported by the National Natural Science Foundation of China (31760046). The supporter provided financial help for experiment design, data collection, data analysis and manuscript writing.

\section{Availability of data and materials}

The datasets generated and analysed during the current study are included in this article, its supplementary information files and in the [NCBI] repository with Accession: PRJNA707665 \& PRJNA604474 [https:// www.ncbi.nIm.nih.gov/sra/PRJNA707665 \& https://www.ncbi.nlm.nih.gov/ sra/PRJNA604474].

\section{Declarations}

Ethics approval and consent to participate Not applicable.

\section{Consent for publication}

I agree to the terms of the BioMed Central Copyright and License Agreement.

\section{Competing interests}

The authors declare that they have no competing interests.

\section{Author details}

${ }^{1}$ College of Life Science, Shihezi University, Shihezi 832003, Xinjiang, China. ${ }^{2}$ Licorice Research Institute of Shihezi University, Shihezi 832003, Xinjiang, China. ${ }^{3}$ Key Laboratory of Xinjiang Phytomedicine Resource Utilization, Ministry of Education, Shihezi University, Shihezi 832003, Xinjiang, China. ${ }^{4}$ Xinjiang Production and Construction Corps Key Laboratory of Oasis Town and Mountain-basin System Ecology, Shihezi University, Shihezi 832003, Xinjiang, China.

Received: 4 July 2021 Accepted: 11 November 2021

Published online: 16 December 2021

\section{References}

1. Fedoroff NV, Battisti DS, Beachy RN, Cooper PJM, Fischhoff DA, Hodges $\mathrm{CN}$, et al. Radically rethinking agriculture for the 21 st century. Science. 2010;327(5967):833-4.

2. Rengasamy P. World salinization with emphasis on Australia. J Exp Bot. 2006;57(5):1017-23.

3. Butcher K, Wick AF, DeSutter T, Chatterjee A, Harmon J. Soil salinity: a threat to global food security. Agron J. 2016;108(6):2189-200.

4. Kaleem F, Shabir G, Aslam K, Rasul S, Manzoor H, Shah SM, et al. An overview of the genetics of plant response to salt stress: present status and the way forward. Appl Biochem Biotechnol. 2018;186(2):306-34.

5. Chinese Pharmacopoeia Commission. Pharmacopoeia of the People's Republic of China, vol. I. Beijing: China Medical Science Press; 2015.

6. Li XY. The ecological distribution of genus Glycyrrhiza and its utilization in Xinjiang. Chin J Plant Ecol. 1986;04:264-71.

7. Qin ZL, Lu JH, Lu S, Tian ZP, Yan P, Bao F. The effect of drip-irrigation cultivated Glycyrrhiza on soil microorganism and salinity content. Xinjiang Agric Sci. 2012;49(10):1920-5.

8. Lu JH, Lv X, Wu Ling, Li XY. Germination responses of three medicinal licorices to saline environments and their suitable ecological regions. Acta Prataculturae Sin. 2013;22(2):195-202.

9. Zhang $A X, L u J H, L i X L, N i u$ QD. Response of root to $\mathrm{Na}+$ and changes of vascular tissue of two Glycyrrhiza species under $\mathrm{NaCl}$ stress. Acta Botan Boreali-Occiden Sin. 2015;35(08):1612-9.

10. Julkowska M, Koevoets IT, Mol S, Hoefsloot HC, Feron R, Tester M, et al. Genetic components of root architecture remodeling in response to salt stress. Plant Cell. 2017;29(12):tpc.00680.02016.

11. Geng $Y, W u R$, Wee CW, Xie F, Xueliang. A spatio-temporal understanding of growth regulation during the salt stress response in Arabidopsis. Plant Cell. 2013;25:2132.

12. Cutler SR, Rodriguez PL, Finkelstein RR, Abrams SR. Abscisic acid: emergence of a core signaling network. In: Merchant S, Briggs WR, Ort D, editors. Annual review of plant biology, vol. 61. Palo Alto: Annual Reviews; 2010. p. 651-79.

13. Tanimoto M, Roberts $K$, Dolan L. Ethylene is a positive regulator of root hair development in Arabidopsis thaliana. Plant J. 1995;8(6):943-8.

14. Yeo AR, Flowers TJ. Accumulation and localisation of sodium ions within the shoots of rice (Oryza sativa) varieties differing in salinity resistance. Physiol Plant. 2010;56(3):343-8.

15. Alassimone J, Naseer S, Geldner N. A developmental framework for endodermal differentiation and polarity. Proc Natl Acad Sci U S A. 2010;107(11):5214-9.

16. Robbins PD, Morelli AE. Regulation of immune responses by extracellular vesicles. Nat Rev Immunol. 2014;14(3):195-208.

17. Naseer S, Lee Y, Lapierre C, Franke R, Nawrath C, Geldner N. Casparian strip diffusion barrier in Arabidopsis is made of a lignin polymer without suberin. Proc Natl Acad Sci U S A. 2012;109(25):10101-6.

18. Schreiber L. Transport barriers made of cutin, suberin and associated waxes. Trends Plant Sci. 2010;15(10):546-53.

19. Barberon M. The endodermis as a checkpoint for nutrients. New Phytol. 2017;213(4):1604-10.

20. Pollard M, Beisson F, Li YH, Ohlrogge JB. Building lipid barriers: biosynthesis of cutin and suberin. Trends Plant Sci. 2008;13(5):236-46.

21. Vishwanath SJ, Delude C, Domergue F, Rowland O. Suberin: biosynthesis, regulation, and polymer assembly of a protective extracellular barrier. Plant Cell Rep. 2015;34(4):573-86. 
22. Wang P, Wang C-M, Gao L, Cui Y-N, Yang H-L, de Silva NDG, et al. Aliphatic suberin confers salt tolerance to Arabidopsis by limiting $\mathrm{Na}+$ influx, $\mathrm{K}+$ efflux and water backflow. Plant Soil. 2020;448(1-2):603-20.

23. Shi HZ, Ishitani M, Kim CS, Zhu JK. The Arabidopsis thaliana salt tolerance gene SOS1 encodes a putative Na+/H+ antiporter. Proc Natl Acad Sci U S A. 2000;97(12):6896-901.

24. Jiang CJ, Li XL, Zou JX, Ren JY, Jin CY, Zhang H, et al. Comparative transcriptome analysis of genes involved in the drought stress response of two peanut (Arachis hypogaea L.) varieties. BMC Plant Biol. 2021;21(1):14.

25. Zhou J, Chen SQ, Shi WJ, David-Schwartz R, Li ST, Yang FL, et al. Transcriptome profiling reveals the effects of drought tolerance in Giant Juncao. BMC Plant Biol. 2021;21(1):20.

26. Feng YN, Cui JQ, Zhou T, Liu Y, Yue CP, Huang JY, et al. Comprehensive dissection into morpho-physiologic responses, ionomic homeostasis, and transcriptomic profiling reveals the systematic resistance of allotetraploid rapeseed to salinity. BMC Plant Biol. 2020;20(1):22.

27. Munns R, Tester M. Mechanisms of salinity tolerance. Annu Rev Plant Biol. 2008:59:651-81.

28. Plett DC, Moller IS. Na plus transport in glycophytic plants: what we know and would like to know. Plant Cell Environ. 2010;33(4):612-26.

29. Huang L, Kuang LH, Li X, Wu LY, Wu DZ, Zhang GP. Metabolomic and transcriptomic analyses reveal the reasons why Hordeum marinum has higher salt tolerance than Hordeum vulgare. Environ Exp Bot. 2018:156:48-61.

30. Munns R, Gilliham M. Salinity tolerance of crops - what is the cost? New Phytol. 2015;208(3):668-73.

31. Lu JH, Lu X, Liang YC, Ling HR. Salt tolerance of Glycyrrhiza inflata seedlings in Xinjiang and its ion response to salt stress. Chin J Plant Ecol. 2013;37(09):839-50.

32. Maathuis FJM, Amtmann A. K+ nutrition and Na+ toxicity: the basis of cellular K+/Na+ ratios. Ann Bot. 1999;84(2):123-33.

33. Munns R. Genes and salt tolerance: bringing them together. New Phytol. 2005;167(3):645-63.

34. Hirschi KD. The calcium conundrum. Both versatile nutrient and specific signal. Plant Physiol. 2004;136(1):2438-42.

35. Choi W-G, Toyota M, Kim S-H, Hilleary R, Gilroy S. Salt stress-induced Ca2+ waves are associated with rapid, long-distance root-to-shoot signaling in plants. Proc Natl Acad Sci U S A. 2014;111(17):6497-502.

36. Seifikalhor M, Aliniaeifard S, Shomali A, Azad N, Hassani B, Lastochkina $\mathrm{O}$, et al. Calcium signaling and salt tolerance are diversely entwined in plants. Plant Signal Behav. 2019;14(11):1665455.

37. Bhattarai S, Liu N, Karunakaran C, Tanino KK, Fu Y-B, Coulman B, et al. Tissue specific changes in elements and organic compounds of alfalfa (Medicago sativa L.) cultivars differing in salt tolerance under salt stress. J Plant Physiol. 2021;264:153485.

38. Yadav NS, Shukla PS, Jha A, Agarwal PK, Jha B. The SbSOS1 gene from the extreme halophyte Salicornia brachiata enhances $\mathrm{Na}+$ loading in xylem and confers salt tolerance in transgenic tobacco. BMC Plant Biol. 2012:12:188.

39. Yang C, Guo W, Shi D. Physiological roles of organic acids in alkalitolerance of the alkali-tolerant halophyte chloris virgata. Agron J. 2010;102(4):1081-9.

40. Ahmed HAl, Shabala L, Shabala S. Tissue-specificity of ROS-induced K+ and $\mathrm{Ca} 2+$ fluxes in succulent stems of the perennial halophyte Sarcocornia quinqueflora in the context of salinity stress tolerance. Plant Physiol Biochem. 2021;166:1022-31.

41. Duchen MR. Mitochondria and $\mathrm{Ca}(2+)$ in cell physiology and pathophysiology. Cell Calcium. 2000;28(5-6):339-48.

42. Carillo P, Cirillo C, De Micco V, Arena C, De Pascale S, Rouphael Y. Morphoanatomical, physiological and biochemical adaptive responses to saline water of Bougainvillea spectabilis Willd. Trained to different canopy shapes. Agric Water Manag. 2019;212:12-22.

43. Montillet JL, Chamnongpol S, Rusterucci C, Dat J, van de Cotte B, Agnel JP, et al. Fatty acid hydroperoxides and $\mathrm{H}_{2} \mathrm{O} 2$ in the execution of hypersensitive cell death in tobacco leaves. Plant Physiol. 2005;138(3):1516-26.

44. Zribi OT, Hessini K, Trabelsi N, Zribi F, Hamdi A, Ksouri R, et al. Aeluropus littoralis maintains adequate gas exchange, pigment composition and phenolic contents under combined effects of salinity and phosphorus deficiency. Aust J Bot. 2017;65(5):453-62.
45. Farhangi-Abriz S, Torabian S. Antioxidant enzyme and osmotic adjustment changes in bean seedlings as affected by biochar under salt stress. Ecotox Environ Safe. 2017;137:64-70.

46. Bassil E, Coku A, Blumwald E. Cellular ion homeostasis: emerging roles of intracellular $\mathrm{NHX} \mathrm{Na/H}$ antiporters in plant growth and development. J Exp Bot. 2012;63(16):5727-40.

47. Peng Z, He S, Sun J, Pan Z, Gong W, Lu Y, et al. $\mathrm{Na}(+)$ compartmentalization related to salinity stress tolerance in upland cotton (Gossypium hirsutum) seedlings. Sci Rep. 2016;6:34548.

48. Kader MA, Seidel T, Golldack D, Lindberg S. Expressions of OsHKT1, OsHKT2, and OsVHA are differentially regulated under $\mathrm{NaCl}$ stress in salt-sensitive and salt-tolerant rice (Oryza sativa L.) cultivars. J Exp Bot. 2006;57(15):4257-68.

49. Qi Z, Hampton CR, Shin R, Barkla BJ, White PJ, Schachtman DP. The high affinity $\mathrm{K}+$ transporter AtHAK5 plays a physiological role in planta at very low $\mathrm{K}+$ concentrations and provides a caesium uptake pathway in Arabidopsis. J Exp Bot. 2008;59(3):595-607.

50. Zhang X, Zhang M, Takano T, Liu S. Characterization of an AtCCX5 gene from Arabidopsis thaliana that involves in high-affinity $\mathrm{K}+$ uptake and $\mathrm{Na}+$ transport in yeast. Biochem Biophys Res Commun. 2011;414(1):96-100

51. Yang TY, Zhang S, Hu YB, Wu FC, Hu QD, Chen G, et al. The role of a potassium transporter OsHAK5 in potassium acquisition and transport from roots to shoots in rice at low potassium supply levels. Plant Physiol. 2014;166(2):945-U757.

52. Voelker C, Schmidt D, Mueller-Roeber B, Czempinski K. Members of the Arabidopsis AtTPK/KCO family form homomeric vacuolar channels in planta. Plant J. 2006;48(2):296-306.

53. De Stefani D, Patron M, Rizzuto R. Structure and function of the mitochondrial calcium uniporter complex. Biochim Biophys Acta-Mol Cell Res. 2015;1853(9):2006-11.

54. De Stefani D, Raffaello A, Teardo E, Szabo I, Rizzuto R. A forty-kilodalton protein of the inner membrane is the mitochondrial calcium uniporter. Nature. 2011;476(7360):336-U104.

55. Steudle E. Water uptake by plant roots: an integration of views. Plant Soil. 2000;226(1):45-56.

56. Nagahashi G, Thomson WW, Leonard RT. The casparian strip as a barrier to the movement of lanthanum in corn roots. Science (New York, NY). 1974;183(4125):670-1.

57. Karahara I, Ikeda A, Kondo T, Uetake Y. Development of the Casparian strip in primary roots of maize under salt stress. Planta. 2004;219(1):41-7.

58. Sanchez-Ballesta MT, Zacarias L, Granell A, Lafuente MT. Accumulation of PAL transcript and PAL activity as affected by heat-conditioning and lowtemperature storage and its relation to chilling sensitivity in mandarin fruits. J Agric Food Chem. 2000;48(7):2726-31.

59. Franke R, McMichael CM, Meyer K, Shirley AM, Cusumano JC, Chapple C. Modified lignin in tobacco and poplar plants over-expressing the Arabidopsis gene encoding ferulate 5-hydroxylase. Plant J. 2000;22(3):223-34.

60. Goujon T, Sibout R, Pollet B, Maba B, Nussaume L, Bechtold N, et al. A new Arabidopsis thaliana mutant deficient in the expression of O-methyltransferase impacts lignins and sinapoyl esters. Plant Mol Biol. 2003;51(6):973-89.

61. Alejandro S, Lee Y, Tohge T, Sudre D, Osorio S, Park J, et al. AtABCG29 is a monolignol transporter involved in lignin biosynthesis. Curr Biol. 2012;22(13):1207-12.

62. Schuetz M, Benske A, Smith RA, Watanabe Y, Tobimatsu Y, Ralph J, et al. Laccases direct lignification in the discrete secondary cell wall domains of protoxylem. Plant Physiol. 2014;166(2):798-U489.

63. Shigeto J, Tsutsumi Y. Diverse functions and reactions of class III peroxidases. New Phytol. 2016;209(4):1395-402.

64. Lee Y, Rubio MC, Alassimone J, Geldner N. A mechanism for localized lignin deposition in the endodermis. Cell. 2013;153(2):402-12.

65. Zhuang Y, Zuo DQ, Tao YH, Cai HQ, Li L. Laccase3-based extracellular domain provides possible positional information for directing Casparian strip formation in Arabidopsis. Proc Natl Acad Sci U S A. 2020;117(27):15400-2.

66. Moura J, Bonine CAV, Viana JDF, Dornelas MC, Mazzafera P. Abiotic and biotic stresses and changes in the lignin content and composition in plants. J Integr Plant Biol. 2010;52(4):360-76. 
67. Hoefer R, Briesen I, Beck M, Pinot F, Schreiber L, Franke R. The Arabidopsis cytochrome P450 CYP86A1 encodes a fatty acid omega-hydroxylase involved in suberin monomer biosynthesis. J Exp Bot. 2008;59(9):2347-60.

68. Molina I, Li-Beisson Y, Beisson F, Ohlrogge JB, Pollard M. Identification of an Arabidopsis feruloyl-coenzyme A transferase required for Suberin synthesis. Plant Physiol. 2009;151(3):1317-28.

69. Berberich T, Harada M, Sugawara K, Kodama H, Iba K, Kusano T. Two maize genes encoding omega-3 fatty acid desaturase and their differential expression to temperature. Plant Mol Biol. 1998;36(2):297-306.

70. Yang WL, Simpson JP, Li-Beisson Y, Beisson F, Pollard M, Ohlrogge JB. A land-plant-specific Glycerol-3-phosphate acyltransferase family in Arabidopsis: substrate specificity, sn-2 preference, and evolution. Plant Physiol. 2012;160(2):638-52

71. Beisson F, Li YH, Bonaventure G, Pollard M, Ohlrogge JB. The acyltransferase GPAT5 is required for the synthesis of suberin in seed coat and root of Arabidopsis. Plant Cell. 2007;19(1):351-68.

72. Schnurr J, Shockey J, Browse J. The acyl-CoA synthetase encoded by LACS2 is essential for normal cuticle development in Arabidopsis. Plant Cell. 2004;16(3):629-42.

73. Bublitz C, Kennedy EP. Synthesis of phosphatides in isolated mitochondria. III. The enzymatic phosphorylation of glycerol. J Biol Chem. 1954;211(2):951-61.

74. Albertyn J, Hohmann S, Thevelein JM, Prior BA. GPD1, which encodes glycerol-3-phosphate dehydrogenase, is essential for growth under osmotic stress in Saccharomyces cerevisiae, and its expression is regulated by the high-osmolarity glycerol response pathway. Mol Cell Biol. 1994;14(6):4135-44.

75. Parsonage D, Luba J, Mallett TC, Claiborne A. The soluble alpha-glycerophosphate oxidase from enterococcus casseliflavus - sequence homology with the membrane-associated dehydrogenase and kinetic analysis of the recombinant enzyme. J Biol Chem. 1998;273(37):23812-22.

76. Kawahara Y, de la Bastide M, Hamilton JP, Kanamori H, McCombie WR, Ouyang S, et al. Improvement of the Oryza sativa Nipponbare reference genome using next generation sequence and optical map data. Rice. 2013;6:10.

77. Kolattukudy PE. Polyesters in higher plants. Adv Biochem Eng Biotechnol. 2001;71:1-49.

78. Yadav V, Molina I, Ranathunge K, Castillo IQ, Rothstein SJ, Reed JW. ABCG transporters are required for Suberin and Pollen wall extracellular barriers in Arabidopsis. Plant Cell. 2014;26(9):3569-88.

79. Møller IS, Tester M. Salinity tolerance of Arabidopsis: a good model for cereals? Trends Plant Sci. 2007;12(12):534-40.

80. Galvan-Ampudia CS, Testerink C. Salt stress signals shape the plant root. Curr Opin Plant Biol. 2011;14(3):296-302.

81. Ding Z, De Smet I. Localised ABA signalling mediates root growth plasticity. Trends Plant Sci. 2013;18(10):533-5.

82. Liu J, Zhu J-K. An Arabidopsis mutant that requires increased calcium for potassium nutrition and salttolerance. Proc Natl Acad Sci U S A. 1997;94(26):14960-4.

83. Kobayashi Y, Yamamoto S, Minami H, Hattori KT. Differential activation of the rice sucrose nonfermenting 1-related protein kinase2 family by hyperosmotic stress and Abscisic acid. Plant Cell. 2004;16(5):1163-77.

84. Tang N, Zhang H, Li X, Xiao J, Xiong L. Constitutive activation of transcription factor OsbZIP46 improves drought tolerance in rice. Plant Physiol. 2012;158(4):1755-68.

85. Ubeda-Tomas S, Beemster GT, Bennett MJ. Hormonal regulation of root growth: integrating local activities into global behaviour. Trends Plant Sci. 2012;17(6):326-31.

86. Dewitte W, Scofield S, Alcasabas AA, Maughan SC, Menges M, Braun N, et al. Arabidopsis CYCD3 D-type cyclins link cell proliferation and endocycles and are rate-limiting for cytokinin responses. Proc Natl Acad Sci U S A. 2007;104(36):14537-42.

87. Riefler M, Novak O, Strnad M, Schmulling T. Arabidopsis cytokinin receptor mutants reveal functions in shoot growth, leaf senescence, seed size germination, root development, and cytokinin metabolism. Plant Cell. 2006;18(1):40-54.

88. Rinaldi MA, Liu J, Enders TA, Bartel B, Strader LC. A gain-of-function mutation in IAA16 confers reduced responses to auxin and abscisic acid and impedes plant growth and fertility. Plant Mol Biol. 2012;79(4-5):359-73.
89. Hodges DM, DeLong JM, Forney CF, Prange RK. Improving the thiobarbituric acid-reactive-substances assay for estimating lipid peroxidation in plant tissues containing anthocyanin and other interfering compounds. Planta. 1999;207(4):604-11.

90. Livak KJ, Schmittgen TD. Analysis of relative gene expression data using real-time quantitative PCR and the $2(\mathrm{~T})$ (-Delta Delta C) method. Methods. 2001;25(4):402-8.

\section{Publisher's Note}

Springer Nature remains neutral with regard to jurisdictional claims in published maps and institutional affiliations.
Ready to submit your research? Choose BMC and benefit from:

- fast, convenient online submission

- thorough peer review by experienced researchers in your field

- rapid publication on acceptance

- support for research data, including large and complex data types

- gold Open Access which fosters wider collaboration and increased citations

- maximum visibility for your research: over 100M website views per year

At BMC, research is always in progress.

Learn more biomedcentral.com/submissions 